doi.org/10.3114/fuse.2019.03.07

\title{
Taxonomic revision and multi-locus phylogeny of the North American clade of Ceratocystis
}

\author{
L.A. Holland ${ }^{1}$, D.P. Lawrence ${ }^{1}$, M.T. Nouri ${ }^{2}$, R. Travadon ${ }^{1}$, T.C. Harrington ${ }^{3}$, F.P. Trouillas ${ }^{2 *}$ \\ ${ }^{1}$ Department of Plant Pathology, University of California, Davis, CA 95616, USA \\ ${ }^{2}$ Department of Plant Pathology, University of California, Kearney Agricultural Research and Extension Centre, Parlier, CA 93648, USA \\ ${ }^{3}$ Department of Plant Pathology and Microbiology, lowa State University, Ames, lowa 50011, USA \\ *Corresponding author: flotrouillas@ucdavis.edu
}

Key words:

almond

Ceratocystidaceae

Ceratocystis canker

new species

taxonomy

\begin{abstract}
The North American clade (NAC) of Ceratocystis includes pathogenic species that infect a wide range of woody hosts. Previous phylogenetic analyses have suggested that this clade includes cryptic species and a paraphyletic $C$. variospora. In this study, we used morphological data and phylogenetic analyses to characterize NAC taxa, including Ceratocystis isolates causing a serious disease of almond trees in California. Phylogenetic analyses based on six gene regions supported two new species of Ceratocystis. Ceratocystis destructans is introduced as the species causing severe damage to almond trees in California, and it has also been isolated from wounds on Populus and Quercus in lowa. It is morphologically similar to C. tiliae, a pathogen on Tilia and the most recently characterized species in the NAC. Ceratocystis betulina collected from Betula platyphylla in Japan is also newly described and is the sister taxon to $C$. variospora. Our six-locus phylogenetic analyses and morphological characterization resolved several cryptic species in the NAC.
\end{abstract}

Effectively published online: 27 February 2019.

\section{INTRODUCTION}

The genus Ceratocystis (Sordariomycetes, Microascales, Ceratocystidaceae) was proposed in 1890 based on C. fimbriata, which was first described as the causal agent of black rot of sweet potato (Ipomoea batatas) in the USA (Halsted 1890). The genus now comprises 39 species (Marin-Felix et al. 2017, Barnes et al. 2018, Liu et al. 2018) and consists of a complex of many cryptic and some host-specialized species (Harrington 2000, Oliveira et al. 2015a) that cause various wilt and canker diseases on a wide range of economically important crops around the world (Kile 1993, Harrington 2013). Hosts impacted by Ceratocystis species include Coffea arabica (coffee), Eucalyptus spp., Ficus carica (fig), Hevea brasiliensis (rubber tree), Mangifera indica (mango), Platanus spp. (sycamore or plane trees), Populus spp. (aspen and other poplars), Prunus spp. (almond and other stone fruits), Quercus spp. (oak) and Theobroma cacao (cacao) (Harrington 2000, 2013, de Beer et al. 2014). Recently, Ceratocystis s. lat. was split into 11 genera (Ambrosiella, Berkeleyomyces, Bretziella, Ceratocystis, Chalaropsis, Davidsoniella, Endoconidiophora, Huntiella, Meredithiella, Phialophoropsis, and Thielaviopsis) based on morphological observations, namely perithecial and ascospore characters, and to a greater extent based on phylogenetic placement (de Beer et al. 2014, 2017, Mayers et al. 2015, 2018, Nel et al. 2018).

Ceratocystis is morphologically defined as species that produce hat-shaped ascospores from brown to black, globose, unornamented perithecial bases with elongated perithecial necks that terminate as aseptate, divergent, and blunt-tipped ostiolar hyphae (de Beer et al. 2014). Long-necked perithecia release sticky masses of ascospores at their terminus (Upadhyay
1981, Seifert et al. 1993, Harrington 2013, de Beer et al. 2014). The asexual thielaviopsis-like morph, is characterized by phialidic conidial ontogeny producing chains of hyaline, singlecelled, cylindrical-shaped conidia, called endoconidia (de Beer et al. 2014). Barrel-shaped conidia (doliiform conidia) may also be produced from similar endoconidiophores, and most species produce dark, thick-walled aleurioconidia that facilitate survival in wood or in soil (Harrington 2013, de Beer et al. 2014).

Ceratocystis species are mainly wound colonizers and include weak to highly virulent pathogens causing disease on diverse woody plant hosts. However, Ceratocystis disease cycles are not well understood due to the diversity of spore types, inoculum sources, and dispersal mechanisms, such as insect vectors, wind, infected planting material, root grafting or mechanical transmission during pruning and harvesting (Harrington 2013). Many Ceratocystis species are adapted for insect dispersal by producing sweet-smelling or fruity volatiles that attract insect vectors (Harrington 1993, Kile 1993, Wingfield et al. 1993). The sticky ascospore masses adhere to insect bodies where they can be easily vectored from one host to another (Malloch \& Blackwell 1993). Ceratocystis fimbriata has nonspecific associations with insects such as sap-feeding beetles (Coleoptera; Nitidulidae), flies (Diptera; Drosophilidae) and ambrosia beetles (Coleoptera; Curculionidae) (Kile 1993). In addition to insect dispersal, Ceratocystis species that produce aleurioconidia are typically soilborne and can be transported in water (Kile 1993, Harrington 2013).

Currently, phylogenetic hypotheses have placed Ceratocystis in four broad geographical clades, the Latin American clade (LAC) (Harrington 2000, Engelbrecht \& Harrington 2005), the North American clade (NAC) (Johnson et al. 2005), the African 
clade (AFC) (Heath et al. 2009, Mbenoun et al. 2014), and the Asian-Australian clade (AAC) (Johnson et al. 2005, Thorpe et al. 2005, Li et al. 2017).

The LAC is represented by $C$. fimbriata which is the pathogen that causes black rot of sweet potato. This pathogen is native to South and Central America and the Caribbean (Harrington et al. 2011) and causes wilt or cankers on coffee, Eucalyptus spp., rubber trees, and mango (Harrington 2013). Species in the LAC are considered to be aggressive pathogens responsible for emerging epidemics when introduced to new hosts and locations, such as the recent outbreak of Ceratocystis wilt on mango in Oman and Pakistan (Al Adawi et al. 2014). Other economically important LAC species include $C$. platani, the causal agent of canker stain on Platanus spp. and C. cacaofunesta, the causal agent of Ceratocystis wilt of $T$. cacao (Engelbrecht \& Harrington 2005). In California, C. platani from the LAC has caused mortality of California sycamores (Platanus racemosa var. racemosa) and plane trees in Modesto, California (Perry \& McCain 1988), and the pathogen was apparently introduced from the eastern USA (Engelbrecht et al. 2005). Most recently, a new Ceratocystis species belonging to the LAC, C. Iukuohia, was identified in Hawai'i and associated with rapid death of 'ōhi'a lehua (Metrosideros polymorpha), a devastating disease on an ecologically important native tree species (Barnes et al. 2018).

The AFC includes $C$. albofundus, a pathogen of black wattle (Acacia mearnsii) in Africa (Wingfield et al. 1996). This species is thought to be native to Africa with two genetically isolated populations, in Uganda and South Africa (Barnes et al. 2005). The AAC is represented by C. pirilliformis (Johnson et al. 2005, Thorpe et al. 2005), a pathogen discovered on Eucalyptus nitens in Australia (Barnes et al. 2003). Other species residing in the AAC include $C$. changhui from Colocasia esculenta in China (Liu et al. 2018) and C. uchidae from C. esculenta in Hawai'i (Li et al. 2017). However, species boundaries within the AAC are unclear and require phylogenetic and taxonomic re-examination ( $\mathrm{Li}$ et al. 2017). Recently, C. huliohia, a newly identified species in the AAC, was described together with $C$. lukuohia (LAC), as a second causal agent of rapid death of 'ōhi'a lehua in Hawai'i (Barnes et al. 2018).

Morphological features have been used to distinguish isolates from the NAC and LAC, most notably, slightly smaller ascospores in the NAC and the presence of a collar at the base of the neck of the perithecium; this diagnostic feature is absent in members of the LAC (Johnson et al. 2005). Within the NAC, Ceratocystis species are distinguished from one another based on the presence or absence of conidial stages, host range, isozyme alleles, and DNA-based phylogenetic analyses (Johnson et al. 2005, de Beer et al. 2014, Oliveira et al. 2015a). Yet, the taxonomy and systematics in the NAC needs more rigorous investigation (Johnson et al. 2005, Oliveira et al. 2015a).

The NAC currently includes five Ceratocystis species that have been isolated from various tree hosts, including Betula, Carya, Celtis, Ostrya, Populus, Prunus, Quercus, Tilia, and Ulmus in Europe, Asia, and North America (Johnson et al. 2005). Currently, the NAC of Ceratocystis is comprised of four strongly supported species including $C$. caryae (Carya spp. and other hosts), C. harringtonii (synonym C. populicola; Populus spp.), C. smalleyi (Carya spp. and an associated bark beetle, Scolytus quadrispinosus), C. tiliae (Tilia americana), and the paraphyletic taxon $C$. variospora. Traditionally, the name $C$. variospora has been used to describe the species infecting oaks (Quercus spp.) in the midwestern USA, but it has been isolated from other hardwood species, and C. variospora currently includes the pathogen on Prunus spp. in California (Johnson et al. 2005). Although isolates of $C$. variospora from oak and Prunus differ in their ITS sequences, they could not be distinguished based on morphology nor host association (Johnson et al. 2005). A new species within $C$. variospora was recently described as $C$. tiliae, a wound-associated pathogen of basswood (Tilia americana) in Nebraska and lowa (Oliveira et al. 2015a). Individual phylogenetic analysis across three loci (LSU, TEF1, and Ceratoplatanin) strongly suggests that $C$. variospora is a paraphyletic taxon as currently defined (Oliveira et al. 2015a). Interfertility tests have shown that isolates from the Quercus lineage ( $C$. variospora s. str.) are only interfertile with each other and not with isolates collected from Betula, Prunus, or Tilia (C. variospora s. lat.) (Johnson et al. 2005), thus supporting a biological species concept in conjunction with host specialization (Oliveira et al. 2015a).

Johnson et al. (2005) proposed that the name $C$. variospora should be applied to the Prunus pathogen in California. The fungus causes Ceratocystis canker of almond (Prunus dulcis) (DeVay et al. 1960) and infects other stone fruits, including apricot (P. armeniaca) and prune (P. domestica) (DeVay et al. 1962). The fungus is thought to colonize wounds made on the bark of trees during mechanical harvest. This disease is ubiquitous in older almond orchards and has recently become a growing concern for young orchards. Almonds are California's most economically important agricultural crop and over $80 \%$ of the global supply is grown in California. Disease symptoms appear as brown to dark brown, shallow (not extending far beyond the cambium), and sunken, cankers. Canker expansion is rapid during the growing season, eventually girdling infected limbs, causing leaves to wilt and branches to dieback. The use of mechanical shakers has led to bark injuries on the trunks of trees and a high incidence of Ceratocystis canker.

The aim of this study was to revisit the taxonomy and phylogeny of Ceratocystis isolates recovered from symptomatic almond trees in California. DNA from cultures linked to ex-type and representative specimens for each species in the NAC were obtained and included in a six-gene phylogeny, utilizing portions of $28 \mathrm{~S}$ (LSU) rDNA, $\beta$-tubulin (TUB2), translation elongation factor 1-alpha (TEF1), mini-chromosome maintenance complex component 7 (MCM7), 60S ribosomal protein RPL10 (60S), and Cerato-platanin (CP) gene fragments to further resolve cryptic species within the NAC of Ceratocystis.

\section{MATERIALS AND METHODS}

\section{Collection of isolates}

Isolates were collected from symptomatic almond trees throughout the major almond producing regions in the Central Valley of California (Table 1). Frequently, isolates were collected from trees that were damaged by mechanical harvesting at the trunk or near large pruning wounds made on the scaffolding branches. Gummosis delineated the margins of the cankers in most cases. Trees exhibiting gummosis and sunken lesions in the bark were sampled using a hatchet. Fungi were isolated from pieces of inner bark $(50 \times 50 \times 5 \mathrm{~mm})$ from the margins of active cankers; the pieces were surface disinfested in $0.6 \%$ sodium hypochlorite for $2 \mathrm{~min}$, rinsed twice with sterile water and patted dry with a paper towel. The inner bark pieces were incubated 


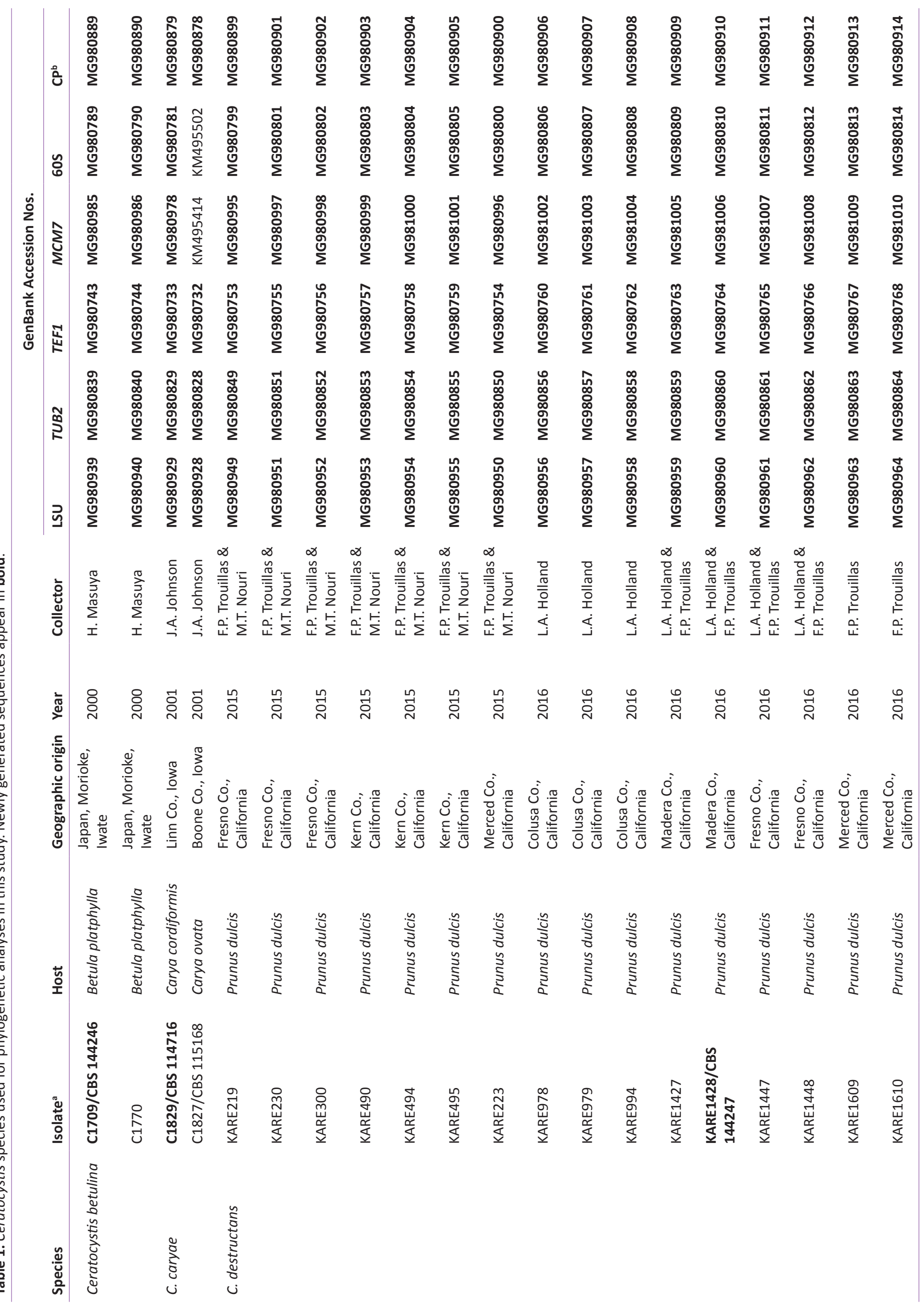




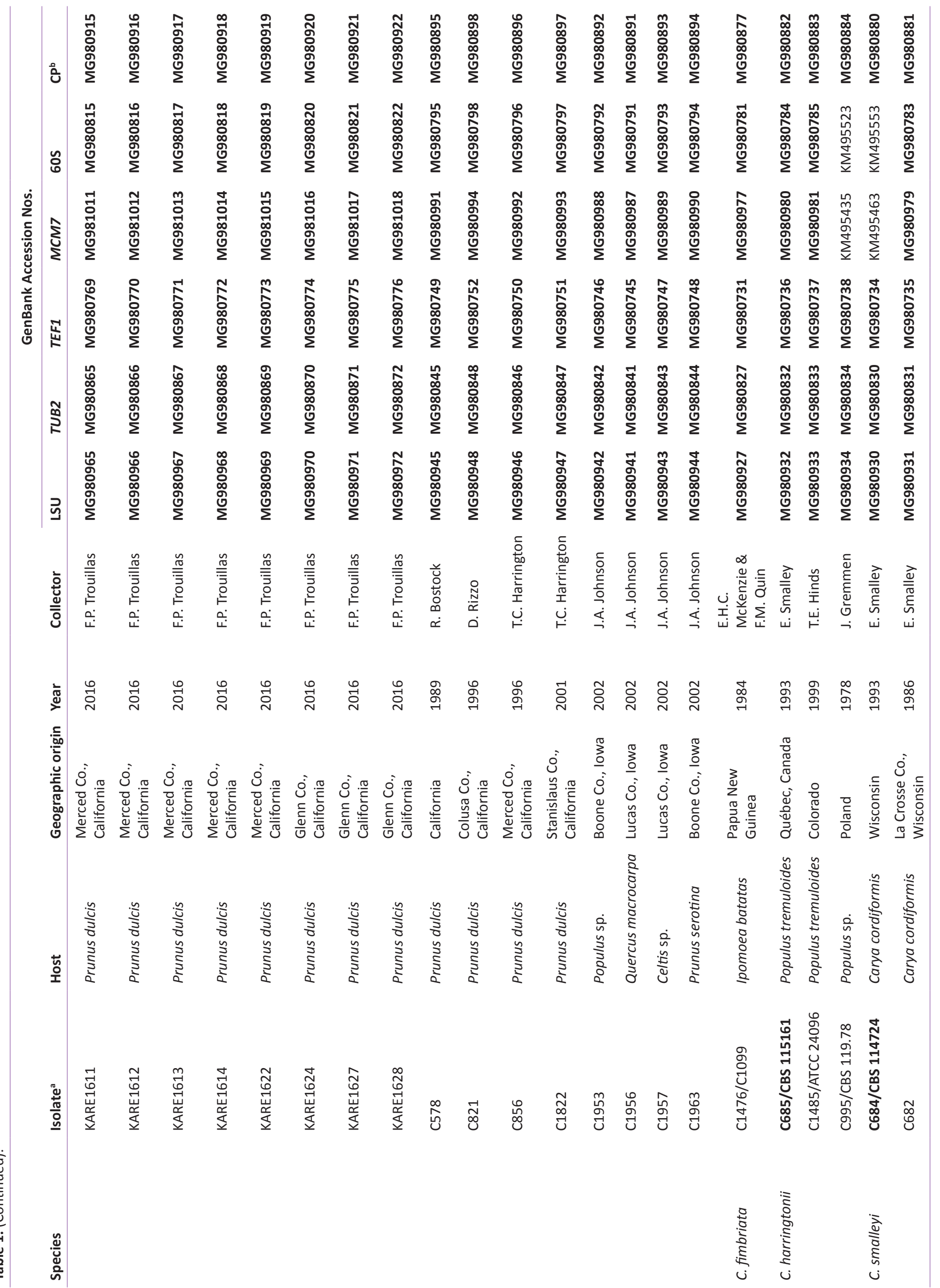


bark-side down (cambium-side up) in a moist chamber (metal mesh rack placed over moistened paper towels in clear plastic boxes) at room temperature for one wk in the laboratory under natural photoperiod to promote perithecia formation. Mats of mycelium typical of Ceratocystis, namely a white wiry mycelium with black, long-necked perithecia extending from the surface of diseased tissue was observed after 5-6 d. Masses of ascospores exuding from the tips of the perithecia were transferred with a sterilized needle to fresh acidified potato dextrose agar (APDA; $2.6 \mathrm{~mL}$ of $25 \%$ [vol/vol] lactic acid per liter of medium) plates followed by hyphal-tip purification to fresh PDA (Potato Dextrose Agar, Difco) filled Petri dishes for additional morphological and phylogenetic analyses. Twentysix isolates including five cultures linked to ex-type specimens of Ceratocystis were obtained from the culture collection of Dr. Thomas C. Harrington, Department of Plant Pathology and Microbiology, lowa State University, corresponding to isolates lodged at the Westerdijk Fungal Biodiversity Institute (former CBS) and are presented in Table 1.

\section{Phylogenetic analyses}

Total genomic DNA was isolated from 24 Californian isolates and an additional 26 NAC isolates from mycelium scraped with a sterile scalpel from the surface of 14-d-old PDA cultures using the DNeasy Plant Kit (Qiagen, Valencia, California), following the manufacturer's instructions. Amplification of translation elongation factor 1- $\alpha$ (TEF1) fragments utilized the primer set EFCF1 and EFCF6 (Harrington 2009), $\beta$-tubulin (TUB2) utilized primers Bt1a and Bt1b (Glass \& Donaldson 1995), the $28 \mathrm{~S}$ (LSU) rDNA region utilized primers LROR and LR7 (Vilgalys \& Hester 1990), Cerato-platanin (CP) utilized primers CP-2F and CP-1R (Pazzagli et al. 1999, Chen et al. 2013), 60S ribosomal protein (60S) utilized primers 60S-506F and 60S-908R (Stielow et al. 2015), and the mini-chromosome maintenance complex component 7 (MCM7) utilized primers Cer-MCM7F and CerMCM7R (de Beer et al. 2014). PCR amplification conditions for the TUB2 and TEF1 regions were the same as those described by Oliveira et al. (2015b); amplification conditions for the cerato-platanin region were the same as those described by Oliveira et al. (2015a), and amplification conditions for the LSU region were the same as those described by Vilgalys \& Hester (1990). A slightly modified PCR program from de Beer et al. (2014) was used for MCM7 and 60S [initial denaturation $\left(96{ }^{\circ} \mathrm{C}, 5 \mathrm{~min}\right.$ ) followed by 35 cycles of denaturation $\left(95^{\circ} \mathrm{C}\right.$, $45 \mathrm{~s})$, annealing $\left(58^{\circ} \mathrm{C}\right.$ for $M C M 7$ and $56{ }^{\circ} \mathrm{C}$ for $60 \mathrm{~S}, 45 \mathrm{~s}$ ), extension $\left(72{ }^{\circ} \mathrm{C}, 60 \mathrm{~s}\right)$, and a final extension $\left.\left(72{ }^{\circ} \mathrm{C}, 10 \mathrm{~min}\right)\right]$. PCR products were visualized on a $1.5 \%$ agarose gel ( $120 \mathrm{~V}$ for $25 \mathrm{~min}$ ) to validate presence and size of amplicons, purified via Exonuclease I and recombinant Shrimp Alkaline Phosphatase (Affymetrix, Santa Clara, California), and sequenced in both directions via BigDye ${ }^{\circledR}$ Terminator v. 3.1 Cycle Sequencing Kit (Thermo Fischer Scientific, Waltham, Massachusetts) on an ABI 3730 Capillary Electrophoresis Genetic Analyzer (College of Biological Sciences Sequencing Facility, University of California, Davis).

Forward and reverse nucleotide sequences were assembled, proofread, and edited in Sequencher v. 5 (Gene Codes Corporation, Ann Arbor, Michigan) and deposited in GenBank (Table 1). Sequences from type and non-type Ceratocystis isolates ( $n=5$ and 21, respectively) in the NAC were included for phylogenetic reference (de Beer et al. 2014, 
Oliveira et al. 2015a) (Table 1). Multiple sequence alignments were performed in MEGA v. 6 (Tamura et al. 2013) and manually adjusted where necessary in Mesquite v. 3.10 (Maddison \& Maddison 2016). Alignments were submitted to TreeBASE under accession number S22454. Concordance among datasets $(P \geq$ 0.010) was evaluated with the partition homogeneity test (PHT) conducted in PAUP v. 4.0b162 (Swofford 2002). Datasets were analyzed using two different optimality search criteria, maximum parsimony (MP) and maximum likelihood (ML), in MEGA v. 6 (Tamura et al. 2013). For MP analyses, heuristic searches with 1000 random sequence additions were implemented with the Tree-Bisection-Reconnection algorithm, gaps were treated as missing data. Bootstrap analysis with 1000 pseudoreplicates was used to estimate branch support. For ML analyses, MEGA was used to infer a model of nucleotide substitution for each dataset, using the Akaike Information Criterion (AIC). ML analysis utilized the Nearest-Neighbor-Interchange heuristic method and branch stability was determined by 1000 bootstrap pseudoreplicates. Sequences of Ceratocystis fimbriata s. str. isolate C1476 from the LAC served as the outgroup taxon in all analyses.

\section{Morphological characterization}

Novel fungal species identified during this study were characterized for morphology. Representative isolates (KARE1428, KARE1610, C578, C821, C1709, and C1770) selected based on phylogenetic results were cultured on MEA ( $2 \%$ Malt Extract Agar; Difco) and PDA. Subculturing was performed by transferring triplicate 5-mm diam mycelial plugs from the colony periphery of a pure culture to the center of fresh Petri dishes filled with MEA and PDA. Cultures were incubated for up to $14 \mathrm{~d}$ at room temperature $\left(24+/-1^{\circ} \mathrm{C}\right)$ with natural ambient day light and darkness at night (Sep. 2017). Radial growth was measured after $7 \mathrm{~d}$ of incubation by taking two measurements at right angles to each other. This experiment was repeated once. Descriptions of colony color (Rayner 1970) and morphology was conducted on day 14. Morphological characterization included measuring the diameter of perithecia and length of ostiolar neck $(n=30)$, length of ostiolar hyphae $(n=30)$, ascospore dimensions $(n=30)$, conidiophores $(n=10)$, dimensions of cylindrical and doliiform conidia $(n=30)$, and aleurioconidia ( $n=30$ ) at $1000 \times$ magnification from 14-d-old cultures by mounting and/or squashing perithecia and other structures in a sterile $50 \%$ glycerol solution on glass slides followed by covering with a glass coverslip and observing structures with a Leica DM500B compound microscope (Leica microsystems $\mathrm{CMS} \mathrm{GmbH}$, Wetzlar, Germany). No stain was applied in order to preserve the natural pigmentation of the fungal specimens. Morphological measurements are represented by the mean and a range depicting the standard deviation in the center with minima and maxima in parentheses, respectively.

Optimal growth temperature for the representative isolates (KARE1428, KARE1610, C578, C821, C1709, and C1770) was assessed by culturing isolates as described above on MEA and PDA in the dark and incubating them at temperatures ranging from $5{ }^{\circ} \mathrm{C}$ to $40{ }^{\circ} \mathrm{C}$ in five degree increments for up to $14 \mathrm{~d}$. Radial colony growth was measured as described above every two days and average colony growth rate and average colony diameter were calculated. Three individual colony replicates per isolate were measured for each temperature. This experiment was repeated once.

\section{RESULTS}

\section{Collection of isolates}

Surveys of almond orchards in California revealed that Ceratocystis canker was widespread throughout the Central Valley region where almond trees are grown. Infections produced gummosis at the margin of active cankers (Fig. 1A, B). Internal symptoms in infected trunks or scaffolds included death of cambium and bark tissues as well as diffuse, dark brown discoloration that extended into the primary and secondary xylem (Fig. 1C). Cankers were generally associated with wounds created by mechanical harvesting and pruning equipment on the tree trunks (Fig. 1A, D-F) or main scaffold branches (Fig. 1B). Wounds caused by mechanical harvesters typically ruptured the bark, thus exposing the susceptible cambial tissues. Cankers expanded along the main axis of the tree, sometimes extending into one of the main scaffolds (Fig. 1A). Isolations from 4-15-yrold trees symptomatic of Ceratocystis canker yielded 87 Ceratocystis isolates from 20 almond orchards in six California counties.

\section{Phylogenetic analyses}

Tests for concordance between datasets using PHT revealed that these data were not significantly inconcordant $(P=0.10)$ and were combined and analyzed as above. For $\mathrm{ML}$ analyses, the best-fit model of nucleotide evolution was selected based on the AIC (K2 for 60S and LSU; K2+G for TEF1, TUB2, MCM7, CP, and the combined analysis).

Alignment of the combined sequences (TEF1+TUB2+CP $+60 S+M C M 7+L S U$ ) resulted in a 4905-character dataset, in which 4432 characters were constant, 198 characters were parsimonyuninformative, and 275 characters were parsimony-informative (6\%). MP analysis generated 8 equally most parsimonious trees of 553 steps and consistency index $(\mathrm{Cl})$, retention index $(\mathrm{RI})$, and rescaled consistency index $(\mathrm{RC})$ of $0.8951,0.9580$, and 0.8523 , respectively. $\mathrm{MP}$ and $\mathrm{ML}$ analyses of the combined six-gene dataset revealed seven strongly supported lineages ( $\geq 91 \%$ / $\geq 99 \% \mathrm{MP}$ and $\mathrm{ML}$ bootstrap values, respectively) within the NAC (Fig. 2). Of these seven lineages, two represent the newly described species hereinafter identified as Ceratocystis betulina sp. nov. and Ceratocystis destructans sp. nov. Ceratocystis betulina was revealed to be the sister taxon to $C$. variospora $s$. str., while $C$. destructans includes the almond pathogen and a group of Ceratocystis isolates collected from Populus, Celtis sp., black cherry (Prunus serotina), and Quercus macrocarpa in lowa. The branch that included only the California isolates (including a single isolate from Populus in lowa) was strongly supported (91\% / $99 \%$ ), but there was only weak support (75 \% / < 70 $\%)$ for the broader $C$. destructans lineage that included all the lowa isolates. The $C$. destructans lineage is sister to the recently described species $C$. tiliae. The order of divergence within the NAC was almost fully resolved, thus providing the first strongly supported hypotheses concerning speciation order within the NAC as depicted in Fig. 2. Thus, the six-gene analysis provides strong support not only for species delineation but also for early and late bifurcations of independently evolving lineages within the NAC.

PCR amplification of the TEF1 locus produced $1433-1473$ bp fragments and resulted in a 1 473-character dataset, in which 1351 characters were constant, 39 were parsimony 

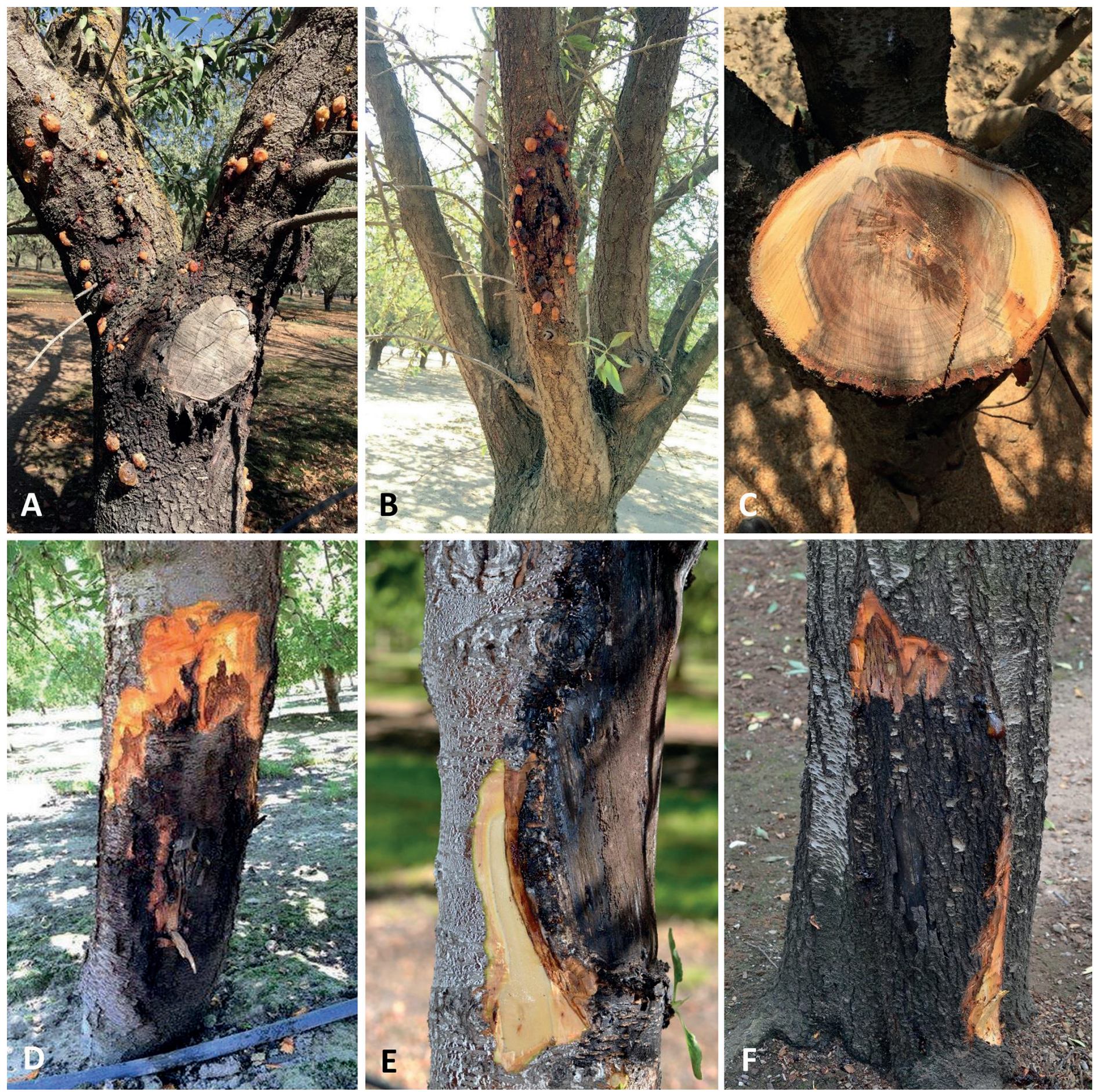

Fig. 1. Symptoms of Ceratocystis canker of almond in California. A. Gummosis and canker associated with a large pruning wound on trunk. B. Scaffold canker. C. Transverse cut of a tree trunk infected with Ceratocystis canker and showing dead cambium and bark tissues as revealed by the brown discoloration extending into the primary and secondary xylem. D-E. Damaged bark and active Ceratocystis cankers developing on the trunk of young almond trees. F. Damaged bark and active Ceratocystis cankers developing on the trunk of a mature almond tree.

uninformative, and 83 were parsimony informative (6\%). The MP analysis produced eight equally most parsimonious trees of 146 steps and a Cl, RI, and RC of $0.8290,0.9529$, and 0.8223 , respectively (Fig. 3A). PCR amplification of the TUB2 locus produced $535-547$ bp fragments and resulted in a 547-character dataset, in which 480 characters were constant, 33 were parsimony uninformative, and 34 were parsimony informative ( $6 \%$ ). The MP analysis produced eight equally most parsimonious trees of 76 steps and $\mathrm{Cl}, \mathrm{RI}$, and RC of 0.8604 , 0.9625 , and 0.8870 , respectively (Fig. $3 B$ ). PCR amplification of the MCM7 locus produced $628 \mathrm{bp}$ fragments and resulted in a 628-character dataset, in which 570 characters were constant, 20 were parsimony uninformative, and 38 were parsimony informative (6\%). The MP analysis produced 10 equally most parsimonious trees of 68 steps and $\mathrm{a} \mathrm{Cl}, \mathrm{RI}$, and RC of 0.9166 , 0.9823 , and 0.9254 , respectively (Fig. 3C). PCR amplification of the 60S locus produced 415-429 bp fragments and resulted in a 429-character dataset, in which 386 characters were constant, 18 were parsimony uninformative, and 25 were parsimony informative (6\%). The MP analysis produced 10 equally most parsimonious trees of 47 steps and a $\mathrm{Cl}, \mathrm{RI}$, and $\mathrm{RC}$ of 0.9574 , 0.9800 , and 0.9385 , respectively (Fig. 3D). PCR amplification of 
Combined Multi-locus Dataset

TEF1/TUB2/MCM7/60S/Cerato-platanin/LSU

8 Trees

568 Steps

$\mathrm{Cl}=0.892606$

$\mathrm{RI}=0.954781$

$\mathrm{RC}=0.852349$
C856 Prunus dulcis California

KARE1627 Prunus dulcis California

KARE1622 Prunus dulcis California

KARE1613 Prunus dulcis California

KARE1611 Prunus dulcis California

KARE1609 Prunus dulcis California

KARE1447 Prunus dulcis California

KARE1427 Prunus dulcis California

KARE979 Prunus dulcis California

KARE495 Prunus dulcis California

KARE490 Prunus dulcis California

KARE230 Prunus dulcis California

KARE219 Prunus dulcis California

$71 / *$

C1822 Prunus dulcis California

C578 Prunus dulcis California

KARE1628 Prunus dulcis California

KARE1624 Prunus dulcis California

KARE1614 Prunus dulcis California

KARE1612 Prunus dulcis California

KARE1610 Prunus dulcis California

KARE1448 Prunus dulcis California

KARE1428/CBS 144227 Prunus dulcis California

KARE994 Prunus dulcis California

KARE978 Prunus dulcis California

KARE494 Prunus dulcis California

KARE300 Prunus dulcis California

KARE223 Prunus dulcis California

C821 Prunus dulcis California

C1953 Populus sp. lowa

C1956 Quercus macrocarpa lowa

C1957 Celtis sp. lowa

L C1963 Prunus serotina lowa

C1959 Tilia americana lowa

C2622 Tilia americana Nebraska

$100 / 100$

C1954 Tilia americana lowa

Ceratocystis tiliae

C2131 Tilia americana lowa

Ceratocystis destructans sp. nov.

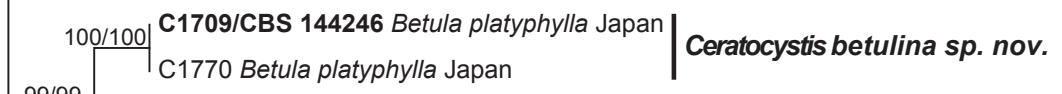

$98 / *$

78/* C1009 Quercus ellipsoidalis Minnesota Ceratocystis variospora

C1483 Quercus ellipsoidalis Minnesota

Ceratocystis harringtonii

100/99 $\quad$ C1485 Populus tremuloides Colorado

— C995 Populus sp. Poland

Ceratocystis caryae

50 Changes

Fig. 2. One of eight equally most parsimonious trees generated from maximum parsimony analysis of the six-gene (TEF1+TUB2+CP+60S+MCM7+LSU) combined dataset. Numbers in front and after the slash represent parsimony and likelihood bootstrap values from 1000 pseudoreplicates, respectively. Values represented by an asterisk were less than $70 \%$ for the bootstrap analyses. Bar indicates the number of nucleotide changes. Ex-type isolates are in bold. 
C

C1953 Populus sp. lowa

KARE1628 Prunus dulcis California

KARE1627 Prunus dulcis California

KARE1624 Prunus dulcis California

KARE1622 Prunus dulcis California

KARE1614 Prunus dulcis California

KARE1613 Prunus dulcis California

KARE1612 Prunus dulcis California

KARE1611 Prunus dulcis California

KARE1610 Prunus dulcis California

KARE1609 Prunus dulcis California

KARE1448 Prunus dulcis California

KARE1447 Prunus dulcis California

KARE1428/CBS 144277 Prunus dulcis California

KARE1427 Prunus dulcis California

KARE994 Prunus dulcis California

KARE979 Prunus dulcis California

KARE978 Prunus dulcis California

KARE495 Prunus dulcis California

KARE494 Prunus dulcis California

KARE490 Prunus dulcis California

KARE300 Prunus dulcis California

KARE230 Prunus dulcis California

KARE223 Prunus dulcis California

KARE219 Prunus dulcis California

C821 Prunus dulcis California

C1822 Prunus dulcis California

C856 Prunus dulcis California

C578 Prunus dulcis California

C1963 Prunus serotina lowa

C1957 Celtis sp. lowa

C1956 Quercus macrocarpa lowa

Ceratocystis destructans sp. nov.

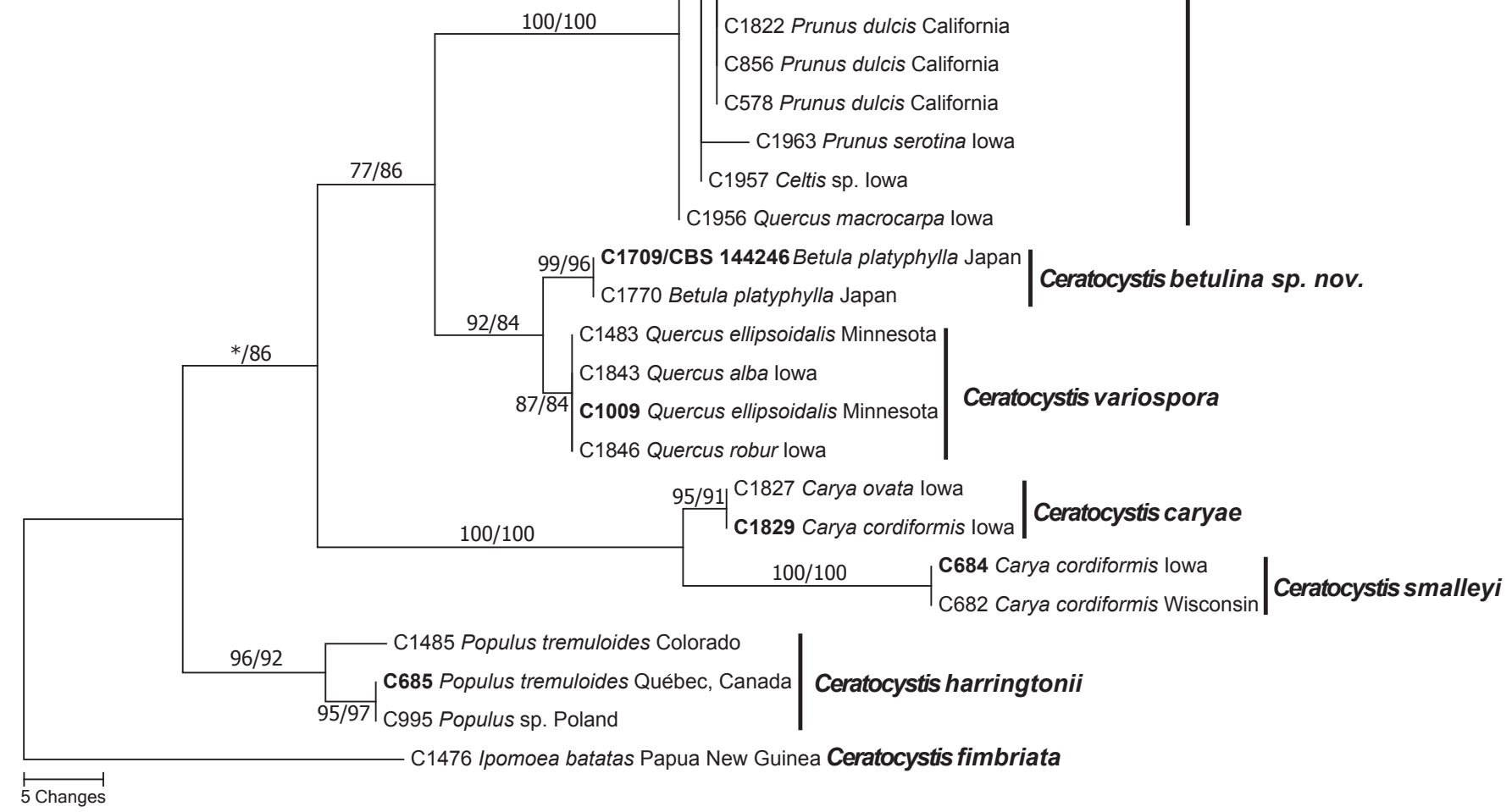

Fig. 3. Equally most parsimonious trees from single-locus analyses. Numbers in front and after the slash represent parsimony and likelihood bootstrap values from 1000 pseudoreplicates, respectively. Values represented by an asterisk were less than $70 \%$ for the bootstrap analyses. The scale bar indicates the number of nucleotide changes. Ex-type isolates are in bold. A. One of eight equally most parsimonious trees for the TEF1 analyses. B. One of eight equally most parsimonious trees for the TUB2 analyses. C. One of 10 equally most parsimonious trees for the MCM7 analyses. D. One of 10 equally most parsimonious trees for the $60 \mathrm{~S}$ analyses. E. One of 10 equally most parsimonious trees for the Cerato-platanin analyses. F. One of 10 equally most parsimonious trees for the LSU analyses. 
TUB2 Dataset 8 Trees

$\mathrm{Cl}=0.860465$

$\mathrm{RI}=0.962500$

$\mathrm{RC}=0.887028$
C578 Prunus dulcis California

KARE1628 Prunus dulcis California

KARE1624 Prunus dulcis California

KARE1614 Prunus dulcis California

KARE1612 Prunus dulcis California

KARE1610 Prunus dulcis California

KARE1448 Prunus dulcis California

KARE1428/CBS 144227 Prunus dulcis California

KARE994 Prunus dulcis California

KARE978 Prunus dulcis California

KARE494 Prunus dulcis California

KARE300 Prunus dulcis California

KARE223 Prunus dulcis California

C821 Prunus dulcis California

C856 Prunus dulcis California

KARE1627 Prunus dulcis California

KARE1622 Prunus dulcis California

KARE1613 Prunus dulcis California

KARE1611 Prunus dulcis California

KARE1609 Prunus dulcis California

KARE1447 Prunus dulcis California

KARE1427 Prunus dulcis California

$70 / *$

KARE979 Prunus dulcis California

KARE495 Prunus dulcis California

KARE490 Prunus dulcis California

KARE230 Prunus dulcis California

KARE219 Prunus dulcis California

C1822 Prunus dulcis California

- C1953 Populus sp. lowa

C1956 Quercus macrocarpa lowa

C1963 Prunus serotina lowa

C1957 Celtis sp. lowa

C2131 Tilia americana lowa

C1954 Tilia americana lowa

C2622 Tilia americana Nebraska

Ceratocystis tiliae

C1959 Tilia americana lowa

Ceratocystis destructans sp. nov.

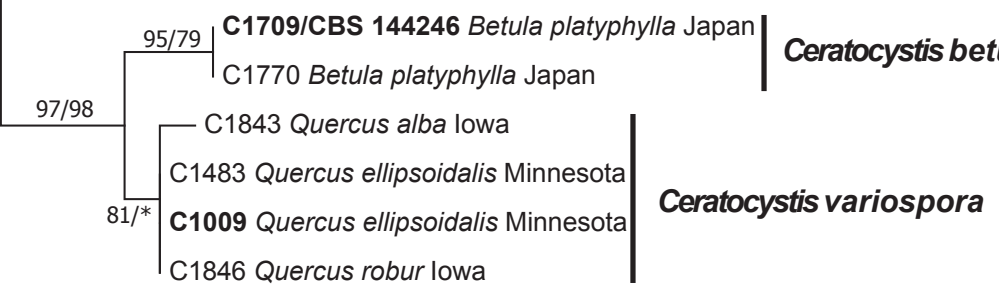

C685 Populus tremuloides Québec, Canada

$96 / 99$

C1485 Populus tremuloides Colorado

C995 Populus sp. Poland

Ceratocystis harringtonii

\begin{tabular}{l|l} 
C682 Carya cordiformis Wisconsin & Ceratocystis smalleyi \\
C684 Carya cordiformis lowa & \\
C1829 Carya cordiformis lowa & \\
C1827 Carya ovata lowa & Ceratocystis caryae
\end{tabular}

C1476 Ipomoea batatas Papua New Guinea Ceratocystis fimbriata

5 Changes

Fig. 3. (Continued). 
MCM7 Dataset

10 Trees

68 Steps

$\mathrm{Cl}=0.916667$

$\mathrm{RI}=0.982301$

$\mathrm{RC}=0.925481$
C1953 Populus sp. lowa

KARE1628 Prunus dulcis California

KARE1627 Prunus dulcis California

KARE1624 Prunus dulcis California

KARE1622 Prunus dulcis California

KARE1614 Prunus dulcis California

KARE1613 Prunus dulcis California

KARE1612 Prunus dulcis California

KARE1611 Prunus dulcis California

KARE1610 Prunus dulcis California

KARE1609 Prunus dulcis California

KARE1448 Prunus dulcis California

KARE1447 Prunus dulcis California

KARE1428/CBS 144227 Prunus dulcis California

$70 / *$

KARE1427 Prunus dulcis California

KARE994 Prunus dulcis California

KARE979 Prunus dulcis California

KARE978 Prunus dulcis California

KARE495 Prunus dulcis California

KARE494 Prunus dulcis California

KARE490 Prunus dulcis California

KARE300 Prunus dulcis California

KARE230 Prunus dulcis California

KARE223 Prunus dulcis California

KARE219 Prunus dulcis California

- C821 Prunus dulcis California

C1822 Prunus dulcis California

C856 Prunus dulcis California

C578 Prunus dulcis California

C1963 Prunus serotina lowa

- C1957 Celtis sp. lowa

C1956 Quercus macrocarpa lowa

C1954 Tilia americana lowa

C2131 Tilia americana lowa

$86 /^{*}$

C2622 Tilia americana Nebraska Ceratocystis tiliae

C1959 Tilia americana lowa

Ceratocystis destructans sp. nov.

Ceratocystis betulina sp. nov.

Ceratocystis variospora

Ceratocystis harringtonii

97/98 97/98 C685 Populus tremuloides Québec, Canada

C1485 Populus tremuloides Colorado

Ceratocystis smalleyi

C1829 Carya cordiformis lowa C1827 Carya ovata lowa

C684 Carya cordiformis lowa

Ceratocystis caryae

C1476 Ipomoea batatas Papua New Guinea Ceratocystis fimbriata

5 Changes

Fig. 3. (Continued). 
60S Datase

10 Trees

47 Steps

$\mathrm{Cl}=0.957447$

$\mathrm{RI}=0.980000$

$\mathrm{RC}=0.938573$

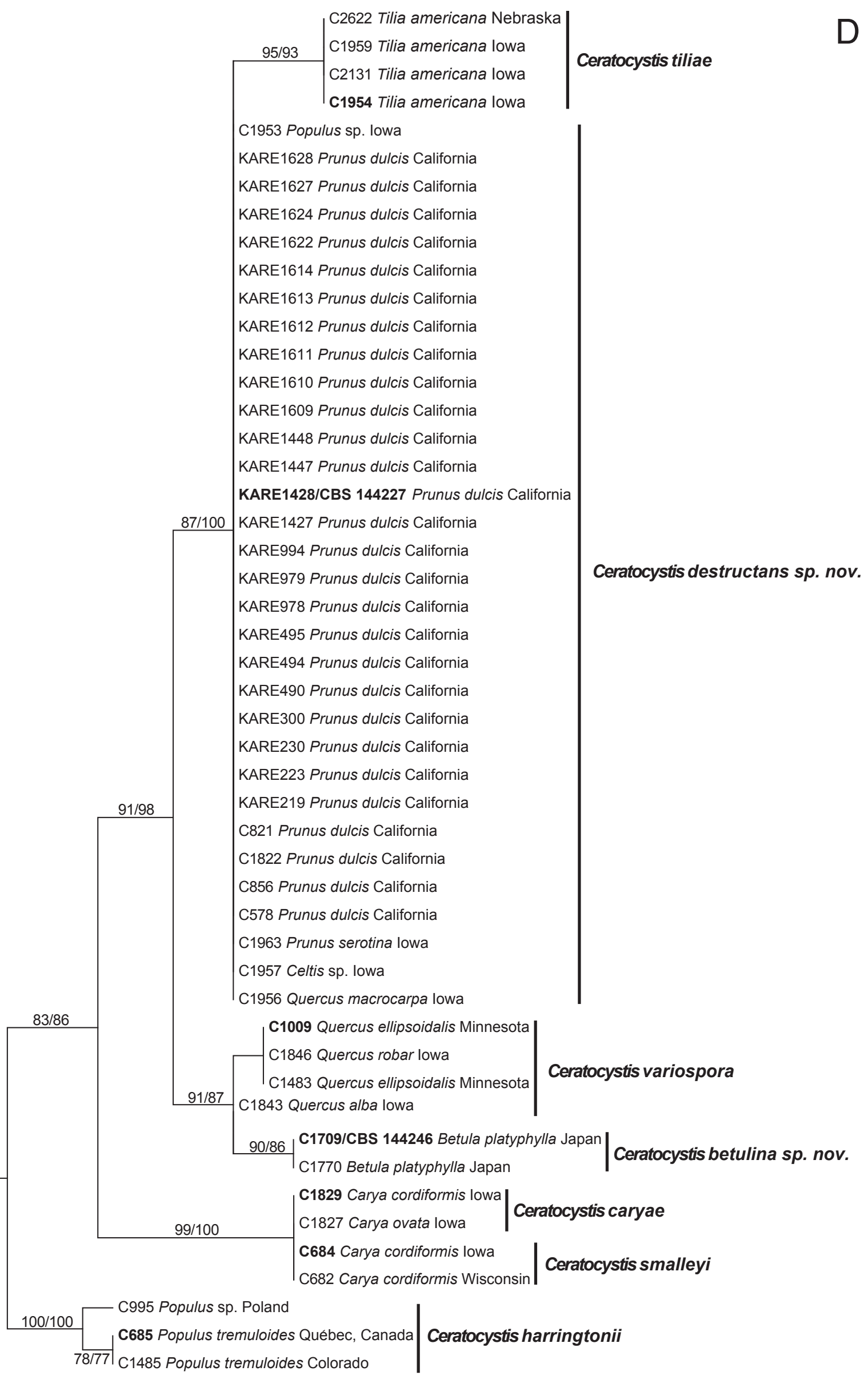

C1476 Ipomoea batatas Papua New Guinea Ceratocystis fimbriata

2 Changes

Fig. 3. (Continued). 
Cerato-platanin Dataset

10 Trees

207 Steps

$\mathrm{Cl}=0.860656$

$\mathrm{RI}=0.957500$

$\mathrm{RC}=0.879513$
$97 / 94$ C1959 Tilia americana lowa

C2131 Tilia americana lowa

C1954 Tilia americana lowa

C1953 Populus sp. lowa

KARE1628 Prunus dulcis California

KARE1627 Prunus dulcis California

KARE1624 Prunus dulcis California

KARE1622 Prunus dulcis California

KARE1614 Prunus dulcis California

KARE1613 Prunus dulcis California

KARE1612 Prunus dulcis California

KARE1611 Prunus dulcis California

KARE1610 Prunus dulcis California

KARE1609 Prunus dulcis California

KARE1448 Prunus dulcis California

KARE1447 Prunus dulcis California

KARE1428/CBS 144227 Prunus dulcis California

KARE1427 Prunus dulcis California

KARE994 Prunus dulcis California

KARE979 Prunus dulcis California

KARE978 Prunus dulcis California

KARE495 Prunus dulcis California

KARE494 Prunus dulcis California

KARE490 Prunus dulcis California

KARE300 Prunus dulcis California

KARE230 Prunus dulcis California

KARE223 Prunus dulcis California

KARE219 Prunus dulcis California

C821 Prunus dulcis California

C1822 Prunus dulcis California

C856 Prunus dulcis California

C578 Prunus dulcis California

C1957 Celtis sp. lowa

$95 / 93$

C1956 Quercus macrocarpa lowa

L 1963 Prunus serotina lowa

C1483 Quercus ellipsoidalis Minnesota

C1843 Quercus robur lowa

98/99 C1009 Quercus ellipsoidalis Minnesota Ceratocystis variospora

C1846 Quercus robur lowa

C1709/CBS 144246 Betula platyphylla Japan

$98 / 97$

Ceratocystis betulina sp. nov.

C1770 Betula platyphylla Japan

Ceratocystis destructans sp. nov.

C1485 Populus tremuloides Colorado

96/82 C685 Populus tremuloides Québec, Canada

94/97 C995 Populus sp. lowa

Ceratocystis harringtonii

\section{Ceratocystis caryae}

\section{Ceratocystis smalleyi}

10 Changes

Fig. 3. (Continued). 


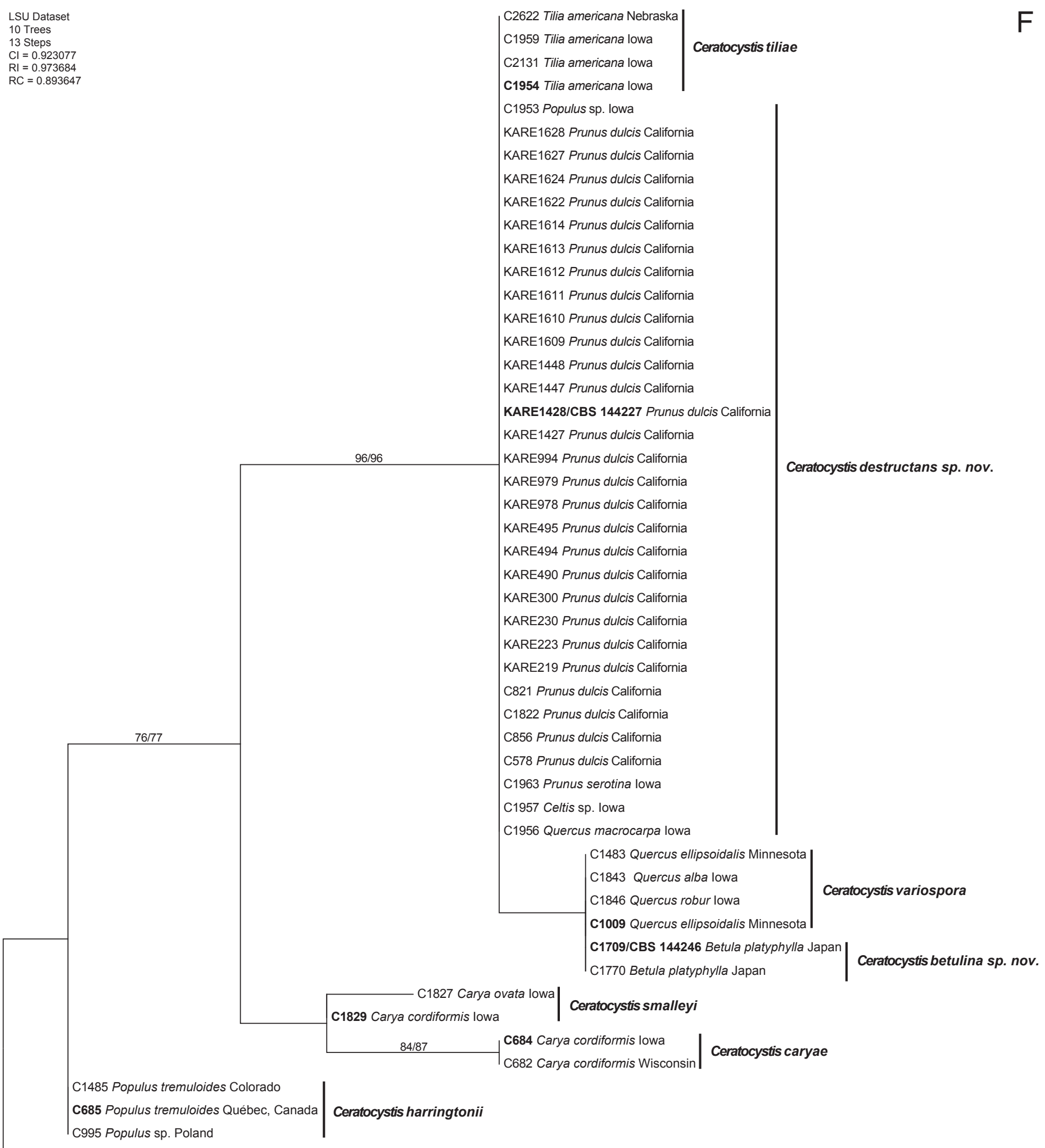

1 Change

Fig. 3. (Continued).

the Cerato-platanin locus produced 487-498 bp fragments and resulted in a 498-character dataset, in which 327 characters were constant, 85 were parsimony uninformative, and 86 were parsimony informative (17.2\%). The MP analysis produced 10 equally most parsimonious trees of 207 steps and a $\mathrm{Cl}, \mathrm{RI}$, and RC of $0.8606,0.9575$, and 0.8795 respectively (Fig. 3E). PCR amplification of LSU produced $1330 \mathrm{bp}$ fragments and resulted in a 1 330-character dataset, in which 1318 characters were constant, three were parsimony uninformative, and nine were parsimony informative (1\%). The MP analysis produced 10 equally most parsimonious trees of 13 steps and a $\mathrm{Cl}, \mathrm{RI}$, and RC of $0.9230,0.9736$, and 0.8936, respectively (Fig. 3F). No single gene fragment was able to confidently recognize all seven lineages within the NAC. Many single gene analyses produced tree topologies that separated most if not all species; however, a lack of support for some phylogenetic positions was realized. 
Results strongly suggest that multiple gene regions are required to accurately separate the more recently diverged species $C$. tiliae and $C$. destructans, while earlier diverging members of the NAC (i.e. C. harringtonii and C. smalleyi) were typically discernible based on fewer loci or even a single locus (i.e. TEF1) (Fig. 3A-F). Only the TEF1 gene region was able to discern the recently diverged $C$. caryae and $C$. smalleyi as separate phylogenetic species, further supporting the use of multiple loci for accurate identification of Ceratocystis species in the NAC.

\section{Morphological characterization}

Isolates representing $C$. betulina (C1709 and C1770) and $C$. destructans (C578, C821, KARE1428, and KARE1610) were used for morphological characterization (Table 2 and Supplementary Table 1). For C. betulina isolates C1709 and C1770, the average colony diameter after $7 \mathrm{~d}$ on PDA and MEA at room temperature $\left(24+/-1^{\circ} \mathrm{C}\right.$ ) was 27 (PDA)/24.2 (MEA) and $23 / 22 \mathrm{~mm}$, respectively. For $C$. destructans isolates C578, C821, KARE1428 and KARE1610 the average colony diameter after $7 \mathrm{~d}$ on PDA and MEA at room temperature $\left(24+/-1^{\circ} \mathrm{C}\right)$ was $36 / 30,35 / 32,40 / 20.3$ and 35/17.3 $\mathrm{mm}$, respectively. In culture, both $C$. betulina and $C$. destructans were slow-growing with even to uneven margins. The colonies of $C$. betulina varied in color from white to grey to olivaceous green. Colonies of $C$. destructans were grey to olivaceous green. Ceratocystis betulina isolate $\mathrm{C} 1770$ produced few perithecia in culture, and the perithecia often lacked necks or had short necks. Ascospores were not observed for this isolate. Isolates of C. destructans produced black ascomata scattered throughout the colony with many perithecia near the colony centre. The ascomatal bases of $C$. destructans isolates ((118-)197(-358) $\mu \mathrm{m})$ were larger than those produced by isolates of $C$. betulina $((103-) 162(-220) \mu \mathrm{m})$. The morphological characters that distinguished $C$. betulina from $C$. destructans were the average diameter of the ascomata and lengths of the necks. Ceratocystis destructans had larger ascomatal diameters (av. ranging from 163-220 $\mu \mathrm{m}$ among the four isolates) and longer necks (av. ranging from 379-623 $\mu \mathrm{m}$ among the four isolates) compared to smaller ascomata (av. of the two isolates $=149 \mu \mathrm{m}$ and 175 $\mu \mathrm{m}$, respectively) and shorter necks (av. of the two isolates $=142$ $\mu \mathrm{m}$ and $298 \mu \mathrm{m}$, respectively) of $C$. betulina. Cylindrical conidia and thick-walled aleurioconidia were abundant in both species and of similar dimensions. Aleurioconidia of $C$. betulina were often found in short chains compared to $C$. destructans, whose aleurioconidia were found singly or in short chains. Doliiform conidia were abundant in $C$. betulina isolates and sparse or absent in C. destructans isolates C578 and C821.

For two isolates of $C$. betulina (C1709 and C1770) and four isolates of $C$. destructans (C578, C821, KARE1428 and KARE1610) the optimal temperature for growth was $25{ }^{\circ} \mathrm{C}$. In general, Ceratocystis destructans grew faster than C. betulina at 5, 10, 15,20 and $35^{\circ} \mathrm{C}$ on PDA. On the other hand, C. betulina isolates grew faster on PDA at the optimal temperature of $25^{\circ} \mathrm{C}$ at an average of $3.5 \mathrm{~mm} / \mathrm{d}$, while $C$. destructans isolates grew at an average of $3.1 \mathrm{~mm} / \mathrm{d}$ on PDA at $25^{\circ} \mathrm{C}$. All isolates grew slower on MEA, with an average growth rate of $0.8 \mathrm{~mm} / \mathrm{d}$ and $1.3 \mathrm{~mm} / \mathrm{d}$ at $25^{\circ} \mathrm{C}$ for $\mathrm{C}$. destructans and $\mathrm{C}$. betulina, respectively. No growth was observed at $40^{\circ} \mathrm{C}$ for any isolates on either growth medium. For both taxa, growth at 5 and $10{ }^{\circ} \mathrm{C}$ was reduced, and an abrupt decline was observed at $35{ }^{\circ} \mathrm{C}$, however $C$. destructans $(25 \mathrm{~mm}$ diam) had almost double the growth of $C$. betulina ( $15 \mathrm{~mm}$ diam) at this temperature after $14 \mathrm{~d}$ on PDA. For both taxa ascomatal production was most abundant when grown at 20 and $25^{\circ} \mathrm{C}$, and no ascomata were produced at 10 and $35^{\circ} \mathrm{C}$.

\section{TAXONOMY}

Morphological comparisons coupled with multi-locus phylogenetic analyses (MP and ML) of the combined six-gene dataset identified two distinct and strongly supported lineages for which no apparent species names exists. Thus, we propose the following new species names to properly circumscribe these unique taxa and to further resolve paraphyletic and cryptic taxa in the NAC.

Ceratocystis betulina D.P. Lawr., L.A. Holland \& Trouillas, sp. nov. MycoBank MB824502. Figs 2, 4.

Etymology: The name refers to the host, Betula platyphylla, from which this fungus was isolated.

Typus: Japan, Morioke, Iwate, isolated from sporulating fungal mat on a log of Betula platyphylla, 22 Sep. 2000, H. Masuya No. C1709 (holotype BPI 910648, dried culture; ex-type culture CBS 144246).

Colonies $24.2 \mathrm{~mm}$ after $7 \mathrm{~d}$ at $25{ }^{\circ} \mathrm{C}$ on MEA, slow-growing with uneven margins and copious aerial hyphae. Hyphae initially hyaline, smooth, straight, branched, septate, becoming dark with age. Mycelium submerged, olivaceous green, aerial mycelium white, producing ascomata in clumps, odor sweet, with banana-like scent. Ascomata perithecial, with bases superficially to partially immersed in the substrate, mostly black, globose, (102.5-)124-174(-193) $\mu \mathrm{m}$ diam, unornamented or with undifferentiated hyphae, collar (32-)43-54(-59.5) $\mu \mathrm{m}$ wide at the base of the perithecial neck. Perithecial necks black, slender, (144.5-)227.5-368(-438) $\mu \mathrm{m}$ long, (14.5-)16.5-22(-24.5) $\mu \mathrm{m}$ wide at the base, (11.5-)13.5-19.5(20) $\mu \mathrm{m}$ wide at the apex. Ostiolar hyphae hyaline, aseptate, straight to flexuous, 22-55 $\mu \mathrm{m}$ long. Asci not seen. Ascospores (4.5-)4.5$5(-5.5) \times(2.5-) 3-3.5(-5) \mu \mathrm{m}$ with outer sheath forming a hatshaped brim. Conidiophores of three types: endoconidiophores lageniform, hyaline to pale brown, septate, 29-67 $\mu \mathrm{m}$ in length, 3-6.5 $\mu \mathrm{m}$ wide at the base and 3-5 $\mu \mathrm{m}$ wide at the mouth, producing hyaline, concatenated, cylindrical conidia (10-)11$15.5(-19) \times(2-) 2.5-3(-3) \mu \mathrm{m}$; other endoconidiophores shorter, 14-33 $\mu \mathrm{m}$ in length, 3-6 $\mu \mathrm{m}$ wide at the base and 3.5-5.5 $\mu \mathrm{m}$ wide at the mouth, producing hyaline, concatenated, smooth-walled, doliiform conidia (5.5-)6-8(-9.5) × (4.5-)5.5-6(-6.5) $\mu \mathrm{m}$; and less abundant, simple conidiophores (21.5-)23-30(-30) × (2.5-)3-5(6) $\mu \mathrm{m}$, producing smooth- and thick-walled, dark brown, ellipsoid to clavate, aleurioconidia (9-)9.5-10.5(-11) × (7.5-)8-8.5(-8.5) $\mu \mathrm{m}$ either singly or in short chains of $2-3$.

Distribution: Morioke, Iwate (Japan).

Additional material examined: Japan, Morioke, Iwate, isolated from Carpophilus sibiricus from a log of Betula platyphylla, 22 Sep. 2000, H. Masuya (C1770).

Notes: Ceratocystis betulina was isolated from a log of Betula platyphylla located near Prunus and Quercus trees. Prior to our analyses, isolates C1709 and C1770 were considered to be $C$. variospora. Phylogenetically, $C$. betulina is strongly supported 


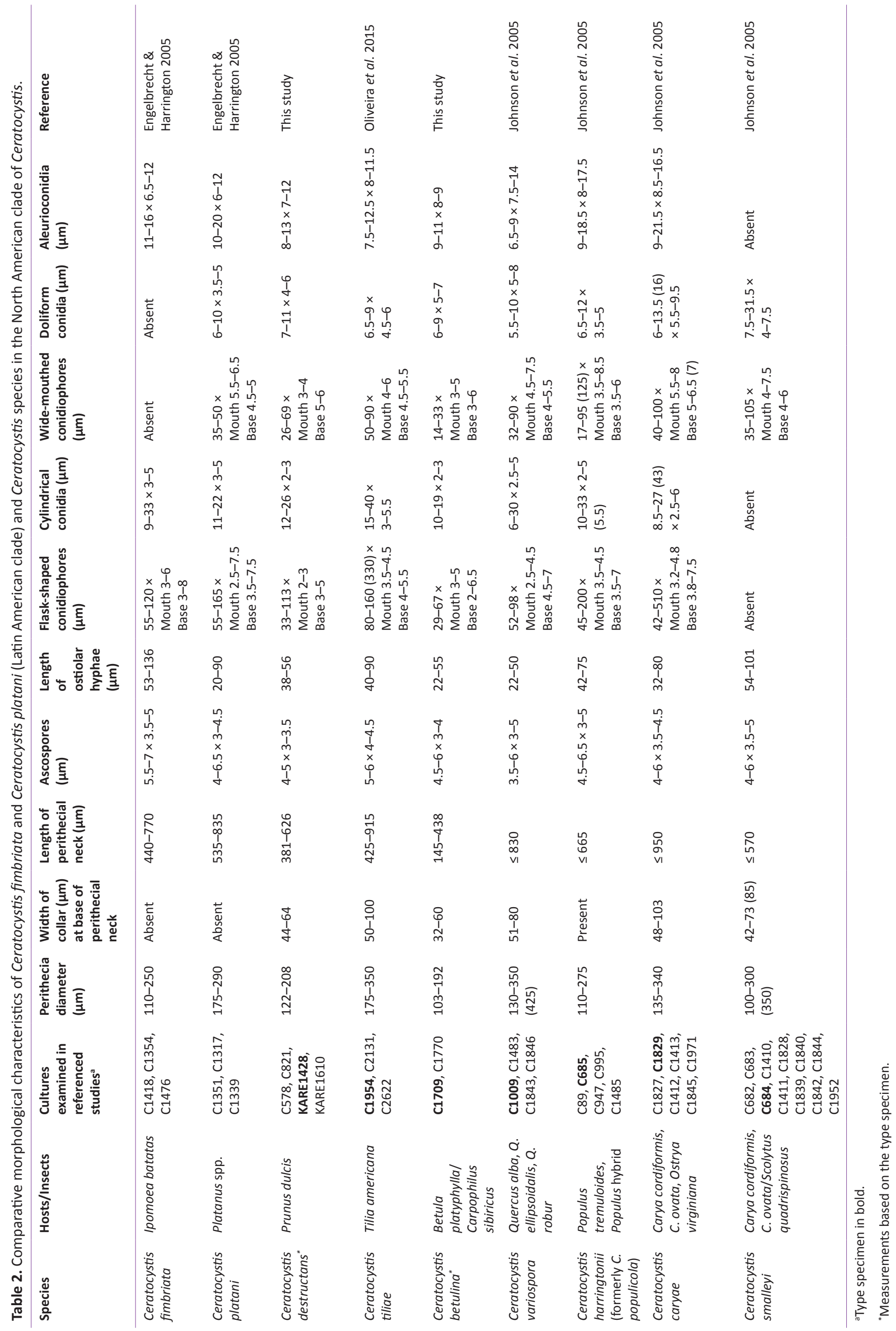



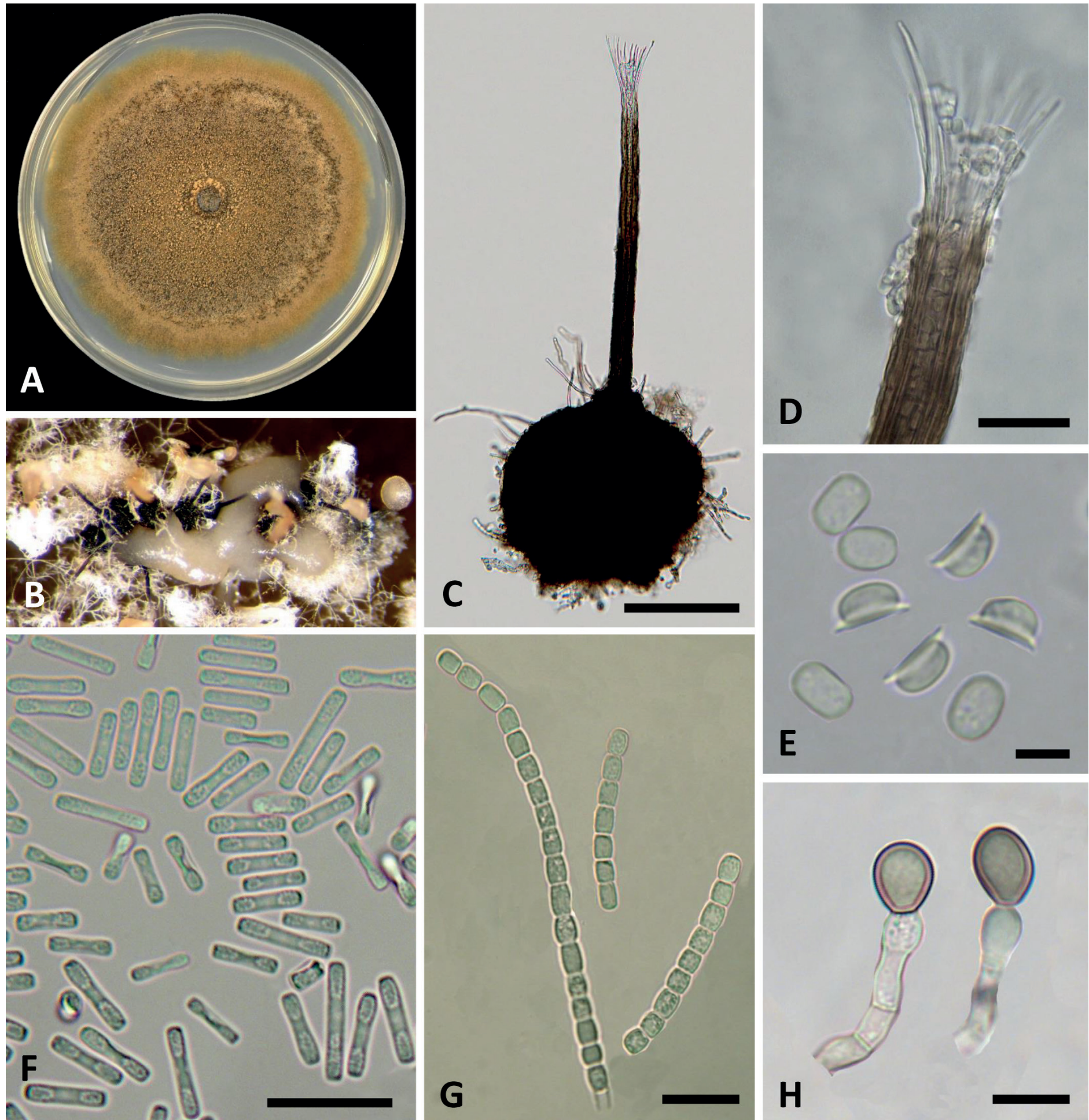

Fig. 4. Morphological characteristics of Ceratocystis betulina. A. 14-d-old PDA culture. B. Close-up of perithecia from 7-d-old culture. C. Globose unornamented ascomata base with elongated neck. D. Straight to flexuous ostiolar hyphae. E. Hat-shaped ascospores from top and side view. F. Cylindrical conidia. G. Short, barrel-shaped conidia. H. Thick-walled aleurioconidia. Scale bars: C = $100 \mu \mathrm{m} ; \mathrm{D}=20 \mu \mathrm{m} ; \mathrm{E}=5 \mu \mathrm{m} ; \mathrm{F}-\mathrm{G}=20 \mu \mathrm{m} ; \mathrm{H}=10 \mu \mathrm{m}$.

as the sister taxon to C. variospora. Morphologically, C. betulina is similar to other members in the NAC and cannot be easily distinguished, though it has somewhat smaller perithecia (102.5-)149(-192) $\mu \mathrm{m}$ diam, shorter, flask-shaped conidiophores (29-67 $\mu \mathrm{m})$, shorter, wide-mouth conidiophores (14-33 $\mu \mathrm{m})$, and smaller aleurioconidia, (9-)10(-11) × (7.5-)8(-8.5) $\mu \mathrm{m}$. Ceratocystis betulina can be distinguished from $C$. variospora based on slightly smaller cylindrical conidia $(10-19 \times 2-3.5 \mu \mathrm{m}$ for C. betulina and 6-30 × 2.5-5 $\mu \mathrm{m}$ for $C$. variospora) (Table 2; Supplementary Table 1$)$.
Ceratocystis destructans L.A. Holland, D.P. Lawr., \& Trouillas, sp. nov. MycoBank MB824558. Figs 2, 5.

Etymology: The name refers to this fungus causing destructive cankers in almond.

Typus: USA, California, Madera County, $36^{\circ} 52^{\prime} 50.3^{\prime \prime} \mathrm{N}$ $119^{\circ} 51^{\prime 25.4 " W}$, isolated from wood canker of Prunus dulcis, 19 Jul. 2016, L.A. Holland No. KARE1428 (holotype BPI 910649, dried culture; ex-type culture CBS 144247). 

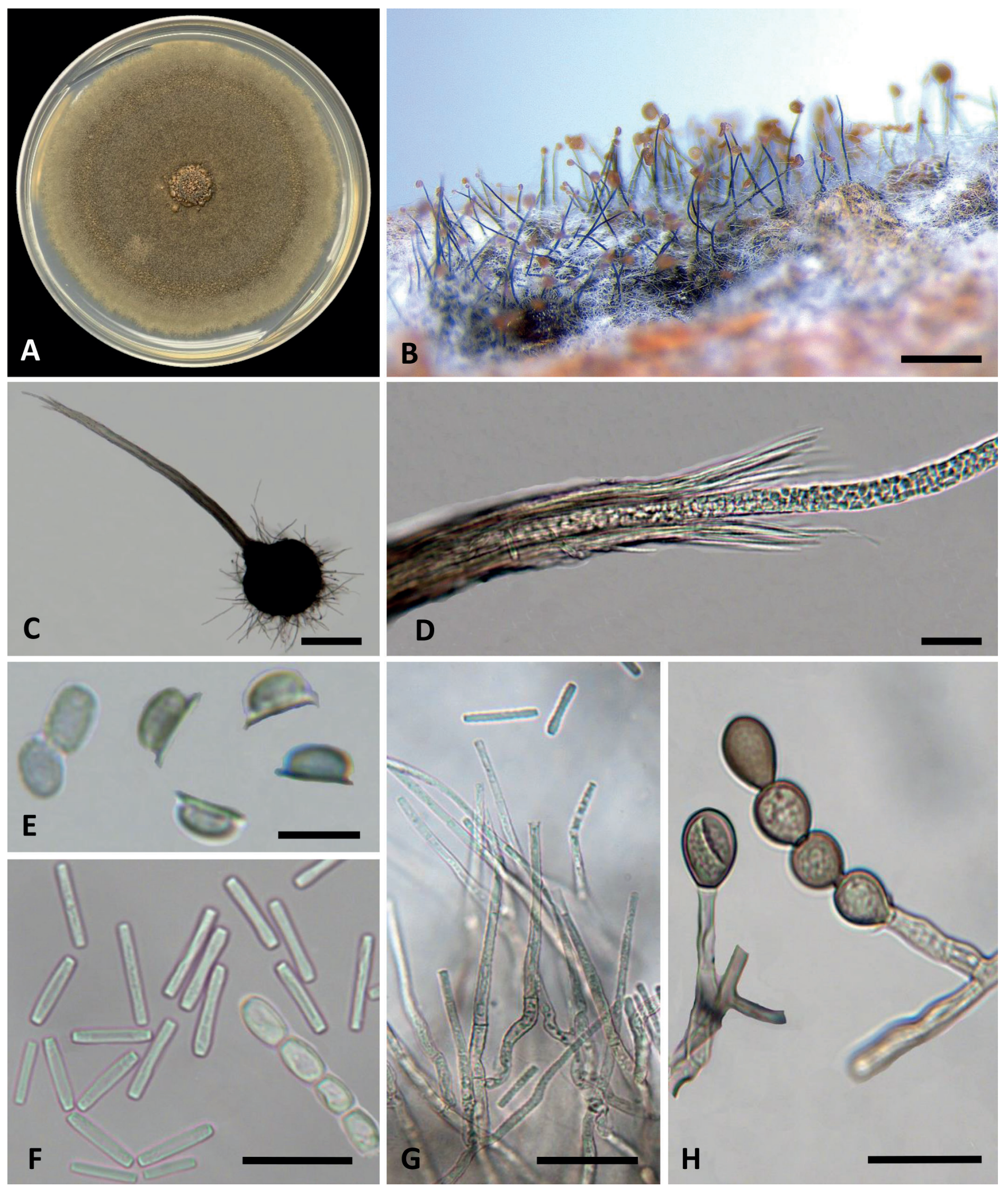

Fig. 5. Morphological characteristics of Ceratocystis destructans. A. 14-d-old PDA culture. B. Close-up of perithecia from 7-d-old culture. C. Globose unornamented ascomata base with elongated neck. D. Mostly straight ostiolar hyphae. E. Hat-shaped ascospores from top and side view. F. Cylindrical and short, barrel-shaped conidia. G. Flask-shaped conidiophores. H. Thick-walled aleurioconidia. Scale bars: B $=500 \mu \mathrm{m} ; \mathrm{C}=100 \mu \mathrm{m} ; \mathrm{D}=25 \mu \mathrm{m} ; \mathrm{E}=$ $5 \mu \mathrm{m} ; \mathrm{F}=25 \mu \mathrm{m} ; \mathrm{G}=20 \mu \mathrm{m} ; \mathrm{H}=25 \mu \mathrm{m}$.

Colonies $20.3 \mathrm{~mm}$ after $7 \mathrm{~d}$ at $25^{\circ} \mathrm{C}$ on MEA, slow-growing with uneven margins and copious aerial hyphae, olivaceous green to brown, aerial hyphae white, odor sweet, with banana-like scent, ascomata produced in clumps or in concentric rings. 
Hyphae initially hyaline, smooth, straight, branched, septate, becoming dark with age. Ascomata perithecial, with bases superficially to partially submerged, mostly black, globose, (121.5-)142-184(-208) $\mu \mathrm{m}$ diam, unornamented or with undifferentiated hyphae, collar (44-)47.5-57(-64) $\mu \mathrm{m}$ wide at the base of the perithecial neck. Perithecial necks black, slender, (382-)434-573(-626) $\mu \mathrm{m}$ long, (13-)18-23.5(-24.5) $\mu \mathrm{m}$ wide at the base, (11-)12-17(-22) $\mu \mathrm{m}$ wide at the apex. Ostiolar hyphae hyaline, aseptate, mostly straight, 38-56 $\mu \mathrm{m}$ long. Asci not seen. Ascospores (5-)4.5-5(-5) × (2.5-)3-3.5(-3.5) $\mu \mathrm{m}$ with outer sheath forming a hat-shaped brim. Conidiophores of three types: endoconidiophores lageniform, hyaline to pale brown, septate, 34-113 $\mu \mathrm{m}$ in length, 3-5 $\mu \mathrm{m}$ wide at the base and $2-3 \mu \mathrm{m}$ at the mouth; producing concatenated, hyaline, cylindrical conidia (12-)14.5-20.5(-26) × (1.5-)2-2.5(-3) $\mu \mathrm{m}$; other endoconidiophores less prevalent and shorter, 26-69 $\mu \mathrm{m}$ in length, 3.5-4 $\mu \mathrm{m}$ wide at the base and 4.5-5.5 $\mu \mathrm{m}$ wide at the mouth, producing hyaline, concatenated, smooth-walled, doliiform conidia (7-)8-10(-10.5) × (4-)4.5-6(-6.5) $\mu \mathrm{m}$; and simple conidiophores not as prevalent, (18-)24-41(-45.5) $\times$ (2.5-)3-3.5(-4), producing smooth- and thick-walled, dark brown, clavate, aleurioconidia (7.5-)9-12(-13) × (7-)8.5-11(13) $\mu \mathrm{m}$ either singly or in short chains of up to four.

Distribution: California (USA), Prunus dulcis; lowa (USA), Prunus serotina, Populus, Celtis and Quercus.

Additional materials examined: USA, California, Colusa County, isolated from bark canker of $P$. dulcis, 1989, R. Bostock (C578); California, Colusa County, isolated from stem canker of $P$. dulcis, 24 Feb. 1996, D. Rizzo (C821); California, Merced County, isolated from bark canker of $P$. dulcis, 8 Sep. 2016, F. Trouillas (KARE1610).

Notes: Ceratocystis destructans has been isolated from almond trees throughout the Central Valley Region of California from necrotic inner bark and wood tissues of trees showing sunken cankers and gummosis. Ceratocystis destructans is morphologically similar to the sister species $C$. tiliae. However, these species can be distinguished based on average ascospore dimensions, with $C$. destructans having slightly smaller ascospores $(4-5 \times 2.5-3.5 \mu \mathrm{m})$ than $C$. tiliae $(5-6 \times 4-4.5 \mu \mathrm{m})$ and smaller ascomata (Table 2; Supplementary Table 1).

\section{DISCUSSION}

Morphological and phylogenetic analyses revealed two novel Ceratocystis species, C. betulina and C. destructans, that reside in the North American clade of Ceratocystis. The NAC of Ceratocystis was established, and the first species delineated by Johnson et al. (2005) based on ITS-rDNA phylogeny, electrophoretic phenotypes, interfertility tests, and crossinoculations experiments. The host-associated lineages included the aspen lineage with $C$. harringtonii (synonym $C$. populicola), the hickory lineage with two species, $C$. caryae and the closely related species $C$. smalleyi, and a third lineage represented by the earlier described C. variospora (Davidson 1944), with two well-supported subclades: the "oak lineage" associated with oak (Quercus) and birch (Betula) and the 'cherry lineage,' mainly associated with cherry and almond (Prunus spp.), Populus, and basswood (Tilia americana). Johnson et al. (2005) hypothesized that host-associated isolates of $C$. variospora from Prunus,
Quercus, and Tilia could represent three separate species, respectively, but these intersterile lineages could not be clearly distinguished by phenotypic traits, i.e., morphology or host specialization to Quercus vs. Prunus spp. Oliveira et al. (2015a), using three individual gene analyses (LSU, TEF1, and CP), showed that Ceratocystis isolates recovered from Tilia clustered as a wellsupported monophyletic group sister to the cherry lineage of $C$. variospora in the TEF1 and CP analyses. Not surprising, limited sequence variation failed to identify sublineages within $C$. variospora in the analysis of LSU, the least informative marker in that study and in our study. Inoculation of Quercus macrocarpa and Tilia americana seedlings demonstrated that only Tiliaderived isolates were aggressive on T. americana, cultures of the Tilia pathogen were distinguished morphologically, and $C$. tiliae was described as new (Oliveira et al 2015a). Like Johnson et al. (2005), Oliveira et al. (2015a) maintained the name C. variospora to accommodate isolates recovered from Betula, Celtis, Populus, Prunus and Quercus, thus leaving $C$. variospora as a paraphyletic species.

Our individual gene analyses produced similar topologies and support values for species assignments as in de Beer et al. (2014) and Oliveira et al. (2015a), highlighting the need for combined multi-locus analyses to discriminate closely related species and to estimate species relationships in the NAC. For example, of the six loci tested, only TEF1 was able to confidently delineate the sister species $C$. caryae and $C$. smalleyi, and all loci except LSU and 60S were able to discern $C$. betulina and $C$. variospora as well-supported sister groups. All loci supported the close relationship of $C$. betulina, C. variospora, C. tiliae, and $C$. destructans, while $C$. harringtonii and $C$. caryae/smalleyi lineages were more distantly related, in agreement with previous studies (Johnson et al. 2005, Oliveira et al. 2015a).

The de Beer et al. (2014) multi-locus analysis (LSU+MCM7 $+60 S$ ) involving NAC members distinguished the ex-type cultures of C. caryae C1829, C. harringtonii C685, C. smalleyi C684, and C. variospora $\mathrm{C} 1009$, but they did not examine the intraspecies diversity of the NAC. Analyses with more isolates of the NAC with phylogenetically informative loci such as TEF1 and CP have revealed greater diversity within the oak and cherry lineages of C. variospora (Oliveira et al. 2015a) as compared to ITS analyses (Johnson et al. 2005). Oliveira et al. (2015a) did not perform a multi-locus analysis because they reported a low $P$ value $(P=0.01)$ for their three-gene PHT. The topology and support values for our TEF1 and CP phylograms are very similar to those reported by Oliveira et al. (2015a). The results of our PHT $(P=0.10)$ and examination of tree topology and support for phylogenetic species recognition utilizing six loci revealed no significant incongruence amongst loci, and the combined analyses resulted in a more robustly supported inference about species recognition (Taylor et al. 2000) and species relationships within the NAC.

The use of multiple phylogenetically informative gene regions has allowed for further taxonomic refinement of species assignments within both the oak and cherry lineages of $C$. variospora. The oak lineage now consists of two robust lineages, which are defined by the species $C$. betulina and $C$. variospora, which was hypothesized by Johnson et al. (2005) and is now strongly supported by multi-locus analyses. The former cherry lineage now consists of two strongly supported phylogenetic lineages, $C$. tiliae and $C$. destructans, as predicted by interfertility tests and distinct mycelial phenotypes, namely the former with slower growth and less pigmentation as compared to the latter 
(Johnson et al. 2005, Oliveira et al. 2015a). The phylogenetic position of three isolates (C1956 from Quercus, C1957 from Celtis, and C1963 from Prunus) from lowa is very close to $C$. destructans, and can be considered this species, but further intersterility testing and phylogenetic analyses would be needed to confidently resolve this small group.

Most Ceratocystis species within the NAC are not only supported by multi-locus phylogenetic analyses but also by host specialization, a biological species concept, and in some cases morphological characters. Host specificity through pathogenicity tests has been demonstrated in the aspen ( $C$. harringtonii) and hickory lineages (C. caryae and C. smalleyi) (Johnson et al. 2005, Oliveira et al. 2015a). Now, with additional locus sampling, the former oak lineage of $C$. variospora consists of two host-associated species, $C$. betulina and $C$. variospora, which have only been isolated from Betula and Quercus, respectively. A clear pattern of host specialization was not as evident in the oak and cherry lineage cross-inoculations, with one exception. Ceratocystis tiliae was more aggressive to Tilia than close relatives isolated from Quercus and vice versa (Oliveira et al. 2015a). Ceratocystis betulina is represented by isolates from a single Betula log, and it is not clear if the log was saprobically colonized or if the fungus was native to Japan. To our knowledge no pathogenicity trials have compared the host associated sister clades $C$. betulina and $C$. variospora, but we predict that some level of host specialization will be realized in this clade as suggested by phylogenetic results. Preliminary pathogenicity trials have shown that isolates of $C$. destructans are highly pathogenic to almond trunks and branches (Holland, unpublished data); however, no cross-inoculation experiments have been performed. Ceratocystis destructans appears to have a rather broad geographic and host range, including Prunus spp. in California as well as Celtis, Populusk, Prunus and Quercus in the Midwest of the USA.

Intersterility tests by Johnson et al. (2005) revealed that MAT2 testers from the cherry, oak and Tilia lineages of $C$. variospora were only interfertile with MAT-1 testers from the same respective lineages, which are now recognized as $C$. destructans, C. variospora and C. tiliae. Two MAT-2 testers from almond trees in California (i.e. C578 and C856) were only interfertile with other isolates now defined as $C$. destructans, including other Californian isolates from almond and lowa isolates from Populus and Quercus. Furthermore, C1709, the ex-type culture of $C$. betulina, was not interfertile with the MAT-2 testers of these species, nor were MAT-1 strains of $C$. harringtonii, $C$. caryae and C. smalleyi interfertile with the MAT-2 testers of $C$. destructans, C. variospora and $C$. tiliae. These examples of reproductive isolation support the recognition of biological species, which together with phylogenetic evidence, supports designation of these lineages as distinct taxa.

Morphology in the NAC was similar for all isolates with some unifying features, such as the ability to produce a second endoconidial stage of doliiform conidia from wide-mouth phialides and a distinct collar at the base of the perithecial neck (Johnson et al. 2005). Within the NAC, morphological features vary only slightly among the different species. For instance, $C$. variospora, which formerly encompassed what is now identified as C. tiliae (Oliveira et al. 2015a), C. destructans and C. betulina, differs morphologically from these species. For example, $C$. variospora possesses larger perithecia (130-350 $\mu \mathrm{m})$, on average, than C. destructans (122-208 $\mu \mathrm{m})$ and C. betulina (103$192 \mu \mathrm{m})$. Ceratocystis variospora also produces slightly larger cylindrical endoconidia than $C$. betulina. However, the overall lack of morphological distinction makes it difficult to recognize these species without molecular characterization. Ceratocystis destructans and $C$. betulina are similar to other species in the NAC, with a dark green to grey colony color, fruity odor, and both cylindrical and doliiform endoconidia, as well as aleurioconidia (Table 2; Supplementary Table 1). Ceratocystis caryae and C. smalleyi (hickory lineage) have very similar ITS sequences and allozyme phenotypes, and they appear to be sexually interfertile (Johnson et al. 2005), but they differ greatly in morphology and biology. Ceratocystis smalleyi lacks cylindrical conidia from flaskshaped phialides and aleurioconidia (Johnson et al. 2005).

Several species in the NAC, including $C$. caryae, $C$. harringtonii, $C$. tiliae and $C$. variospora, are most commonly associated with wounded trunks and branches of trees (Johnson et al. 2005, Oliveira et al. 2015a), suggesting that members of this clade may act primarily as wound colonizers. Ceratocystis destructans is proposed as the new name for the causal agent of Ceratocystis canker of almond in California. The disease is common in California almond orchards where the trees have suffered repeated bark injuries during mechanical harvest, and C. destructans has been routinely isolated from discolored inner bark of almond trees that have been damaged by mechanical harvesting equipment. Ceratocystis destructans can also infect almond trees at wounds caused by pruning, producing branch cankers that result in extensive branch dieback. Several insects have been identified in California almond orchards as potential vectors, including several species of sap-feeding beetles (Coleoptera; Nitidulidae) and fruit flies (Diptera: Drosophilidae) (Moller \& DeVay 1968). These insects are attracted to the sweetsmelling volatile compounds produced by Ceratocystis, and thus the insects may transport infectious spore inoculum from one tree to another. The pathogenicity to almond of $C$. destructans isolates collected for this study was recently investigated. Results showed that this fungus can produce cankers and cause extensive gumming in trunks and branches of almond (Holland et al. 2017). The host range of $C$. destructans in California and the occurrence of putative natural inoculum sources in the native vegetation surrounding almond orchards are unknown. Yet, $C$. destructans has been isolated from Populus spp. and Quercus spp. in the eastern USA. The occurrence in California of $C$. destructans on similar or related plant species should be investigated to better understand the pathogens' biology and putative origin as Ceratocystis canker continues to threaten the almond industry in California.

\section{ACKNOWLEDGEMENTS}

We thank the Almond Board of California for the financial support of this research. Hayato Masuya kindly provided Ceratocystis isolates from Betula logs in Japan.

\section{REFERENCES}

Al Adawi AO, Barnes I, Khan IA, et al. (2014). Clonal structure of Ceratocystis manginecans populations from mango wilt disease in Oman and Pakistan. Australasian Plant Pathology 43: 393-402.

Barnes I, Roux J, Wingfield BD, et al. (2003). Ceratocystis pirilliformis, a new species from Eucalyptus nitens in Australia. Mycologia 95: 865-871. 
Barnes I, Nakabonge G, Roux J, et al. (2005). Comparison of populations of the wilt pathogen Ceratocystis albifundus in South Africa and Uganda. Plant Pathology 54: 189-195.

Barnes I, Fourie A, Wingfield MJ, et al. (2018). New Ceratocystis species associated with rapid death of Metrosideros polymorpha in Hawai'i. Persoonia 40: 154-181.

Chen H, Kovalchuck A, Keriö S, et al. (2013). Distribution and bioinformatic analysis of the cerato- platanin protein family in Dikarya. Mycologia 105: 1479-1488.

Davidson RW (1944). Two American hardwood species of Endoconidiophora described as new. Mycologia 36: 300-306.

de Beer ZW, Duong TA, Barnes I, et al. (2014). Redefining Ceratocystis and allied genera. Studies in Mycology 79: 187-219.

de Beer ZW, Marincowitz S, Duong TA, et al. (2017). Bretziella, a new genus to accommodate the oak wilt fungus, Ceratocystis fagacearum (Microascales, Ascomycota). MycoKeys 27: 1-19.

DeVay JE, English H, Lukezix FL, et al. (1960). Mallet wound canker of almond trees. California Agriculture 14: 8-9.

DeVay JE, Lukezix FL, English H, et al. (1962). Ceratocystis canker. California Agriculture 16: 1-3.

Engelbrecht CJB, Harrington TC (2005). Intersterility, morphology and taxonomy of Ceratocystis fimbriata on sweet potato, cacao and sycamore. Mycologia 97: 57-69.

Glass NL, Donaldson GC (1995). Development of primer sets designed for use with the PCR to amplify conserved genes from filamentous ascomycetes. Applied and Environmental Microbiology 6: 1323-1330.

Halsted BD (1890). Some fungous diseases of the sweet potato. Bulletin of the New Jersey Agricultural Experiment Station 76: 3-32.

Harrington TC (1993). Biology and taxonomy of fungi associated with bark beetles. In: Beetle-pathogen Interactions in Conifer Forests (Schowalter TD, ed). Academic Press, USA: 37-58.

Harrington TC (2000). Host specialization and speciation in the American wilt pathogen Ceratocystis fimbriata. Fitopatologia Brasileira 25 (Suppl): 262-263.

Harrington TC (2009). The genus Ceratocystis: Where does the oak wilt fungus fit? In: Proceedings of the National Oak Wilt Symposium, $2^{\text {nd }}$ (Appel DN, Billings RF, eds). USA: 27-41.

Harrington TC (2013). Ceratocystis diseases. In: Infectious Forest Diseases (Gonthier P, Nicolotti G, eds). CAB International, England: 230-255.

Harrington TC, Thorpe DJ, Alfenas AC (2011). Genetic variation and variation in aggressiveness to native and exotic hosts among Brazilian populations of Ceratocystis fimbriata. Phytopathology 101: 555-566.

Heath RN, Wingfield MJ, Wingfield BD, et al. (2009). Ceratocystis species on Acacia mearnsii and Eucalyptus spp. in eastern and southern Africa including six new species. Fungal Diversity 34: 41-68.

Holland LA, Nouri MT, Morris N, et al. (2017). Almond Trunk and Scaffold Canker Diseases in California: Diagnosis, Pathogenicity, and Management [Abstract]. American Phytopathological Society Annual Meeting, San Antonio, TX.

Johnson JA, Harrington TC, Engelbrecht CJB (2005). Phylogeny and taxonomy of the North American clade of the Ceratocystis fimbriata complex. Mycologia 97: 1067-1092

Kile GA (1993). Plant diseases caused by species of Ceratocystis sensu stricto and Chalara. In: Ceratocystis and Ophiostoma: Taxonomy, Ecology and Pathogenicity (Wingfield MJ, Seifert KA, Webber JF, eds). APS Press, USA: 173-183.

Li Q, Harrington TC, McNew D, et al. (2017). Ceratocystis uchidae, a new species on Araceae in Hawai i and Fiji. MycoScience 58: 398-412.

Liu FF, Barnes I, Roux J, et al. (2018). Molecular phylogenetics and microsatellite analysis reveal a new pathogenic Ceratocystis species in the Asian-Australian clade. Plant Pathology 67: 1097-1113. https://doi.org/10.1111/ppa.12820.

Maddison WP, Maddison DR (2016). Mesquite: a modular system for evolutionary analysis. Version $3.10 \mathrm{http}: / /$ mesquiteproject.org.

Malloch D, Blackwell M (1993). Dispersal biology of the ophiostomatoid fungi. In: Ceratocystis and Ophiostoma: Taxonomy, Ecology and Pathogenicity (Wingfield MJ, Seifert KA, Webber JF, eds). APS Press, USA: 195-206.

Marin-Felix Y, Groenewald JZ, Cai L, et al. (2017). Genera of phytopathogenic fungi: GOPHY 1. Studies in Mycology 86: 99-216.

Mayers CG, McNew DL, Harrington TC, et al. (2015). Three genera in the Ceratocystidaceae are the respective symbionts of three independent lineages of ambrosia beetles with large, complex mycangia. Fungal Biology 119: 1075-1092.

Mayers CG, Bateman CC, Harrington TC (2018). New Meredithiella species from mycangia of Corthylus ambrosia beetles suggest genus-level coadaptation but not species-level coevolution. Mycologia 110: 63-78.

Mbenoun M, Wingfield MJ, Begoude Boyogueno AD, et al. (2014). Molecular phylogenetic analyses reveal three new Ceratocystis species and provide evidence for geographic differentiation of the genus in Africa. Mycological Progress 13: 219-240.

Moller WJ, DeVay JE (1968). Insect transmission of Ceratocystis fimbriata in deciduous fruit orchards. Phytopathology 58: 1499-1508.

Nel WJ, Duong TA, Wingfield BD, et al. (2018). A new genus and species for the globally important, multihost root pathogen Thielaviopsis basicola. Plant Pathology 67: 871-882.

Oliveira LSS, Harrington TC, Freitas RG, et al. (2015a). Ceratocystis tiliae sp. nov., a wound pathogen on Tilia americana. Mycologia 107: 986-995.

Oliveira LSS, Harrington TC, Ferreira MA, et al. (2015b). Species or genotypes? Reassessment of four recently described species of the Ceratocystis wilt pathogen, Ceratocystis fimbriata, on Mangifera indica. Phytopathoogy. 105: 1229-1244.

Pazzagli L, Cappugi G, Manao G, et al. (1999). Purification, characterization and amino acid sequence of cerato-platanin, a new phytotoxic protein from Ceratocystis fimbriata f. sp. platani. Journal of Biological Chemistry 274: 24949-24964.

Perry E, McCain AH (1988). Incidence and management of canker stain in London plane trees in Modesto, California. Journal of Arboriculture 14: 18-19.

Rayner RW (1970). A mycological colour chart. Commonwealth Mycological Institute and British Mycological Society.

Seifert KA, Wingfield MJ, Kendrick WB (1993). A nomenclator for described species of Ceratocystis, Ophiostoma, Ceratocystiopsis, Ceratostomella and Sphaeronaemella. In: Ceratocystis and Ophiostoma: Taxonomy, Ecology and Pathogenicity (Wingfield MJ, Seifert KA, Webber JF, eds). APS Press, USA: 269-287.

Stielow JB, Lévesque CA, Seifert KA et al. (2015). One fungus, which genes? Development and assessment of universal primers for potential secondary fungal DNA barcodes. Persoonia 35: 242-263.

Swofford DL (2002). PAUP* 4: phylogenetic analysis using parsimony (*and other methods). Sunderland, Massachusetts: Sinauer Associates.

Tamura K, Stetcher G, Peterson D, et al. (2013). MEGA 6: Molecular Evolutionary Genetics Analysis version 6.0. Molecular Biology and Evolution 30: 2725-2729.

Taylor JW, Jacobson DJ, Kroken S, et al. (2000). Phylogenetic species recognition and species concepts in fungi. Fungal Genetics and Biology 31: 21-32.

Thorpe DJ, Harrington TC, Uchida JY (2005). Pathogenicity, internal transcribed spacer-rDNA variation, and human dispersal of 


\section{Holland et al.}

Ceratocystis fimbriata on the family Araceae. Phytopathology 95: 316-323.

Upadhyay H (1981). A monograph of Ceratocystis and Ceratocystiopsis. University of Georgia Press, USA.

Vilgalys R, Hester M (1990). Rapid genetic identification and mapping of enzymatically amplified ribosomal DNA from several Cryptococcus species. Journal of Bacteriology 174: 4238-4246.

Wingfield MJ, Seifert KA, Webber JF (1993). Ophiostoma and Ceratocystis: Taxonomy, Ecology and Pathogenicity. APS Press, USA.

Wingfield MJ, De Beer C, Visser C, et al. (1996). A New Ceratocystis species defined using morphological and ribosomal DNA sequence comparisons. Applied Microbiology 19: 191-202.

\section{Supplementary Material: http://fuse-journal.org/}

Table. S1. Additional specimens of $C$. betulina and $C$. destructans examined. 